Support information

\title{
Charge Tags for Most Comprehensive ESI-MS Monitoring of Morita- Baylis-Hillman (MBH)/aza-MBH Reactions: Solid Mechanistic View and the Dualistic Role of the Charge Tagged Acrylate
}

Renan Galaverna, ${ }^{\mathrm{a}^{*}}$ Nilton S. Camilo, ${ }^{\mathrm{b}}$ Marla N. Godoi, ${ }^{\mathrm{c}}$ Fernando Coelho ${ }^{\mathrm{b} *}$ and Marcos N. Eberlin $^{\mathrm{a}}$.

\footnotetext{
${ }^{a}$ Thomson Mass Spectrometry Laboratory, Institute of Chemistry, University of Campinas UNICAMP, CEP 6154 13083-970 Campinas, SP, Brazil

${ }^{\mathrm{b}}$ Laboratory of Synthesis of Natural Products and Drugs, Institute of Chemistry, University of Campinas- UNICAMP, CEP 6154 13083-970, Campinas, SP, Brazil. Email: coelho@iqm.unicamp.br

${ }^{\mathrm{c}}$ Health Sciences Federal University of Porto Alegre - UFCSPA, Department of Pharmacoscience Sarmento Leite, CEP 90050-170, Porto Alegre, RS, Brazil.

* Correspondence to Renan Galaverna, Thomson Mass Spectrometry Laboratory, Institute of Chemistry, State University of Campinas - UNICAMP, CEP 6154 13083-970 Campinas, SP, Brazil. E-mail: renan.galaverna@iqm.unicamp.br, Phone: +55 (19) 35213049.
}

\section{Table of Contents}

1. Materials and Methods

2. NMR spectra $\left({ }^{1} \mathrm{H}\right.$ and $\left.{ }^{13} \mathrm{C}\right)$

3. ESI(+)-MS monitoring using charge tagged benzaldehyde

4. Participation of the charge tagged acrylate on the mechanism of the the monitoring of the neutral and charge tagged $M B H / a z a-M B H$ reactions 
1. Materials and Methods: All reactions were carried out on normal atmosphere, in round bottom flask fitted with magnetic stirring, unless otherwise noted. Commercially available reagents and solvents were used without further purification.

Organic solutions were concentrated under reduced pressure. Reactions were monitored by thin-layer chromatography (TLC). Chromatograms were visualized by fluorescence quenching with UV light at $254 \mathrm{~nm}$ or by staining using phosphomolybdic acid or vanillin solutions. Flash column chromatography was performed using silica gel (particle size $35-70 \mu \mathrm{m}) .{ }^{1} \mathrm{H}$ and ${ }^{13} \mathrm{C}$ NMR spectra were recorded on a $250 \mathrm{MHz}$ spectrometer. Chemical shifts $(\delta)$ are given in parts per million, referenced to the residual peak of $\mathrm{CDCl}_{3}, \mathrm{MeOD}$ and $\left(\mathrm{CD}_{3}\right)_{2} \mathrm{SO}, \delta=7.26 ; 3.35 ; 4.78$ and 2.54 respectively $\left({ }^{1} \mathrm{H} \mathrm{NMR}\right)$ and $\delta=77.0 ; 49.0$ respectively $\left({ }^{13} \mathrm{C} \mathrm{NMR}\right)$ as internal references. 


\section{NMR Spectra}

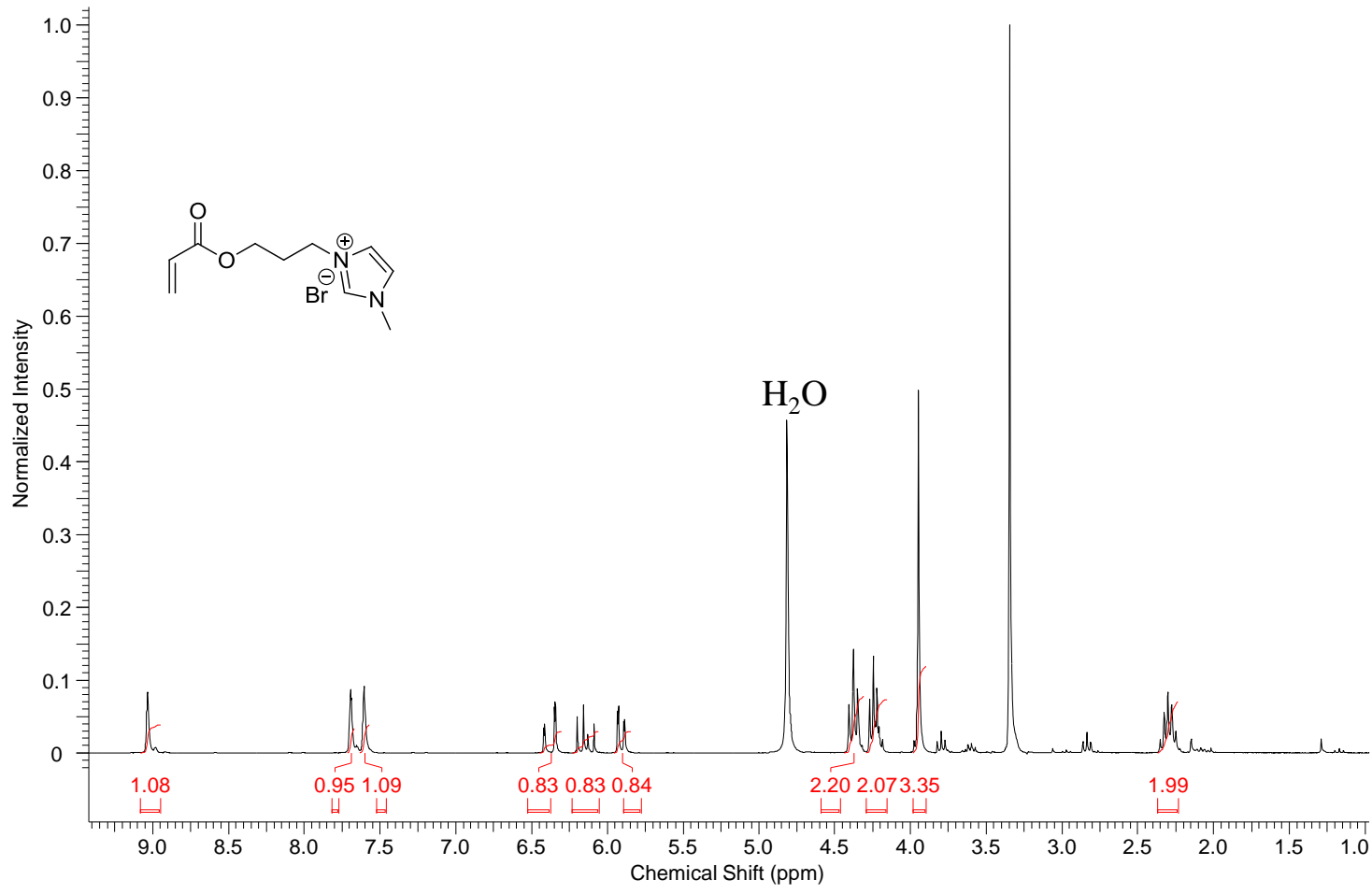

Figure S1. ${ }^{1} \mathrm{H}$ NMR $\left(250 \mathrm{MHz}, \mathrm{CD}_{3} \mathrm{OD}\right)$ spectrum of charge tagged acrylate $\mathbf{5 a}$

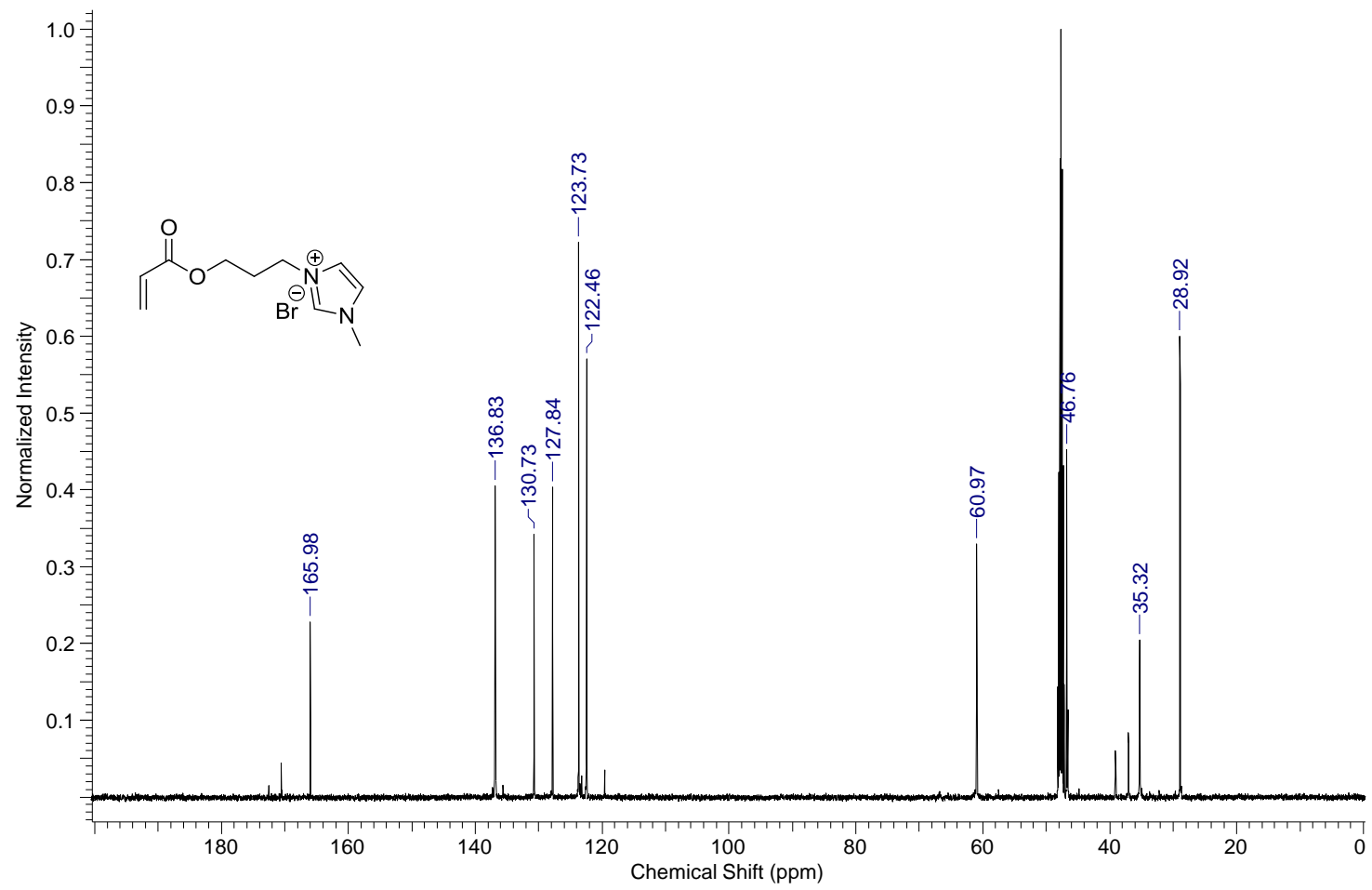

Figure S2. ${ }^{13} \mathrm{C}$ NMR $\left(62.5 \mathrm{MHz}, \mathrm{CD}_{3} \mathrm{OD}\right)$ spectrum of charge tagged acrylate 5a 


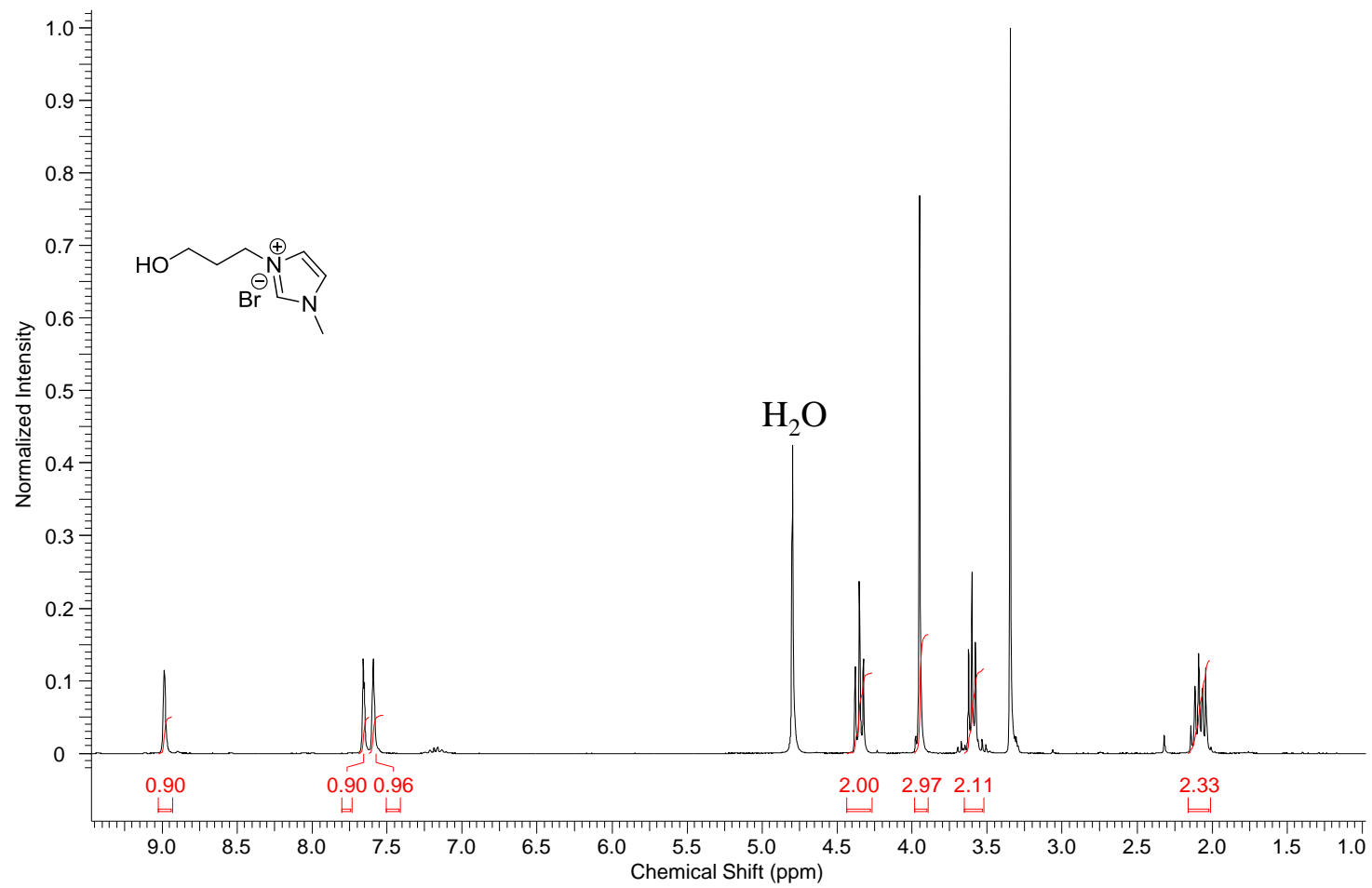

Figure S3. $\quad{ }^{1} \mathrm{H} \quad \mathrm{NMR} \quad\left(250 \quad \mathrm{MHz}, \quad \mathrm{CD}_{3} \mathrm{OD}\right)$ spectrum of 1-(3-Hydroxypropyl)-3methylimidazolium bromide

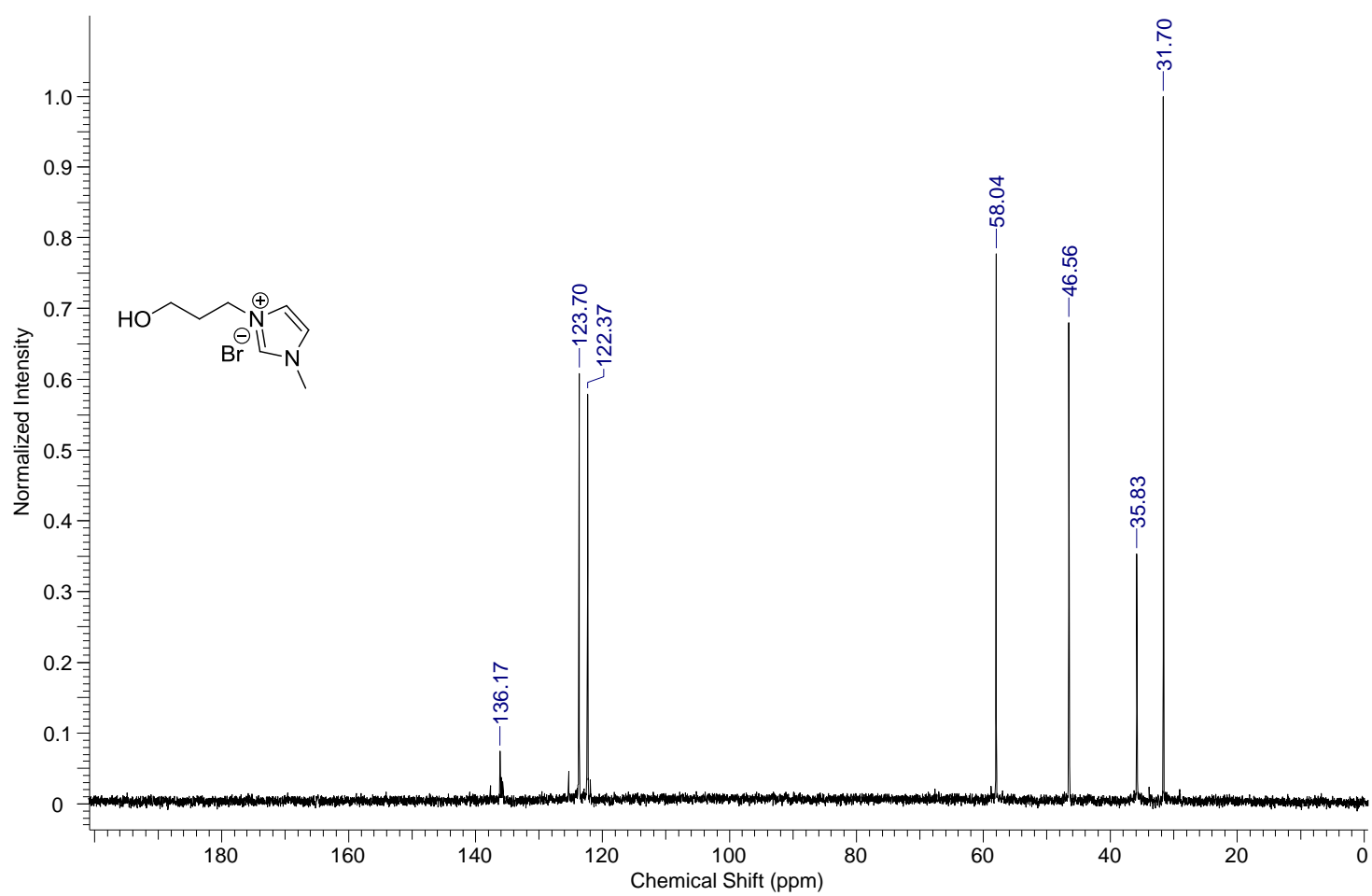

Figure S4. ${ }^{13} \mathrm{C}$ NMR (62.5 MHz, $\mathrm{D}_{2} \mathrm{O}$ ) spectrum of 1-(3-Hydroxypropyl)-3 methylimidazolium bromide 


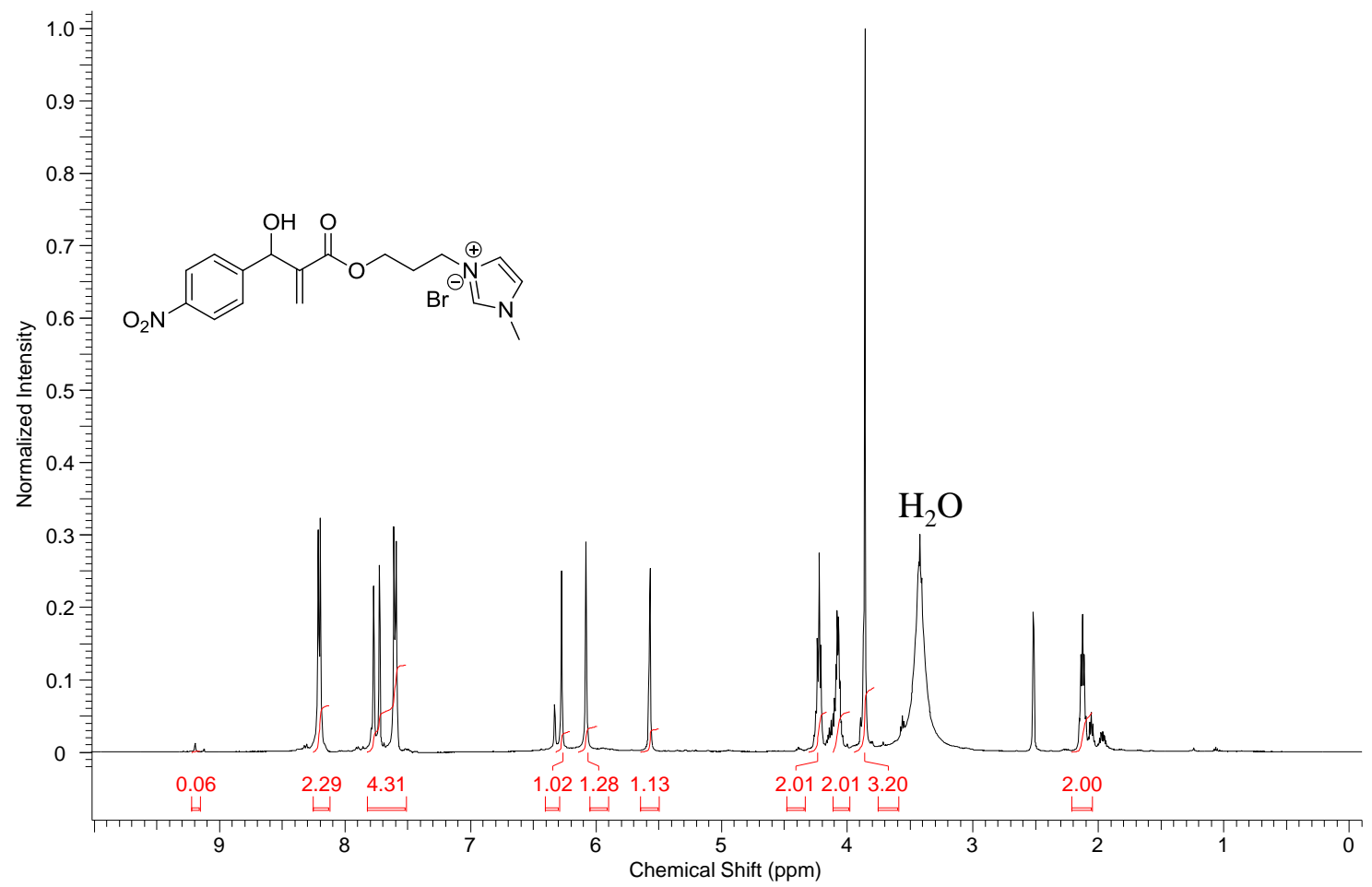

Figure S5. ${ }^{1} \mathrm{H}$ NMR $\left(250 \mathrm{MHz}, \mathrm{CD}_{3} \mathrm{OD}\right)$ spectrum of charge tagged $\mathrm{MBH}$ adduct 10a (Low intensity of methylimidazolium hydrogen due its acidity forming a carbine).

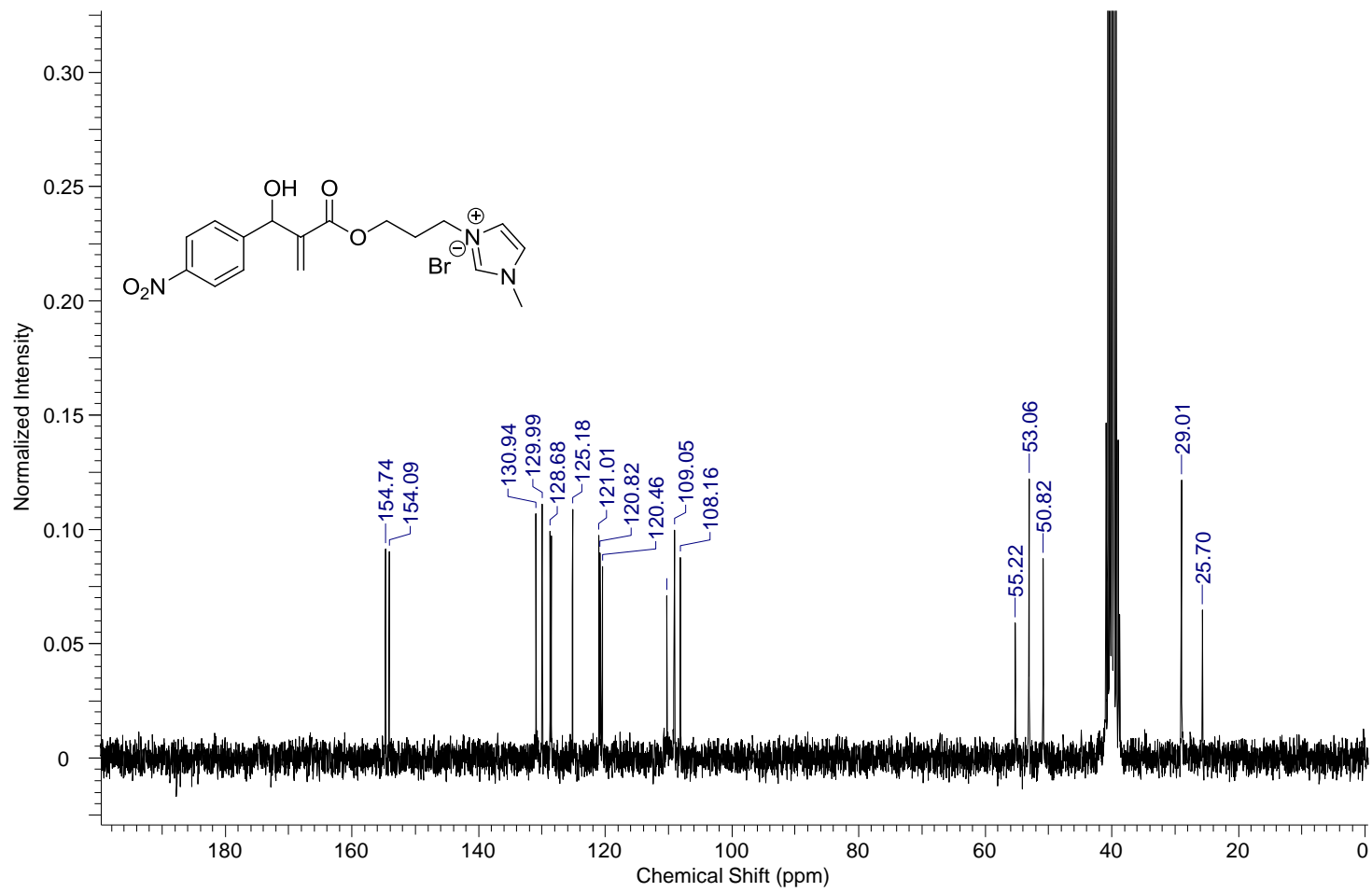

Figure S6. ${ }^{13} \mathrm{C}$ NMR $\left(62.5 \mathrm{MHz}, \mathrm{CD}_{3} \mathrm{OD}\right)$ spectrum of charge tagged $\mathrm{MBH}$ adduct 10a. 


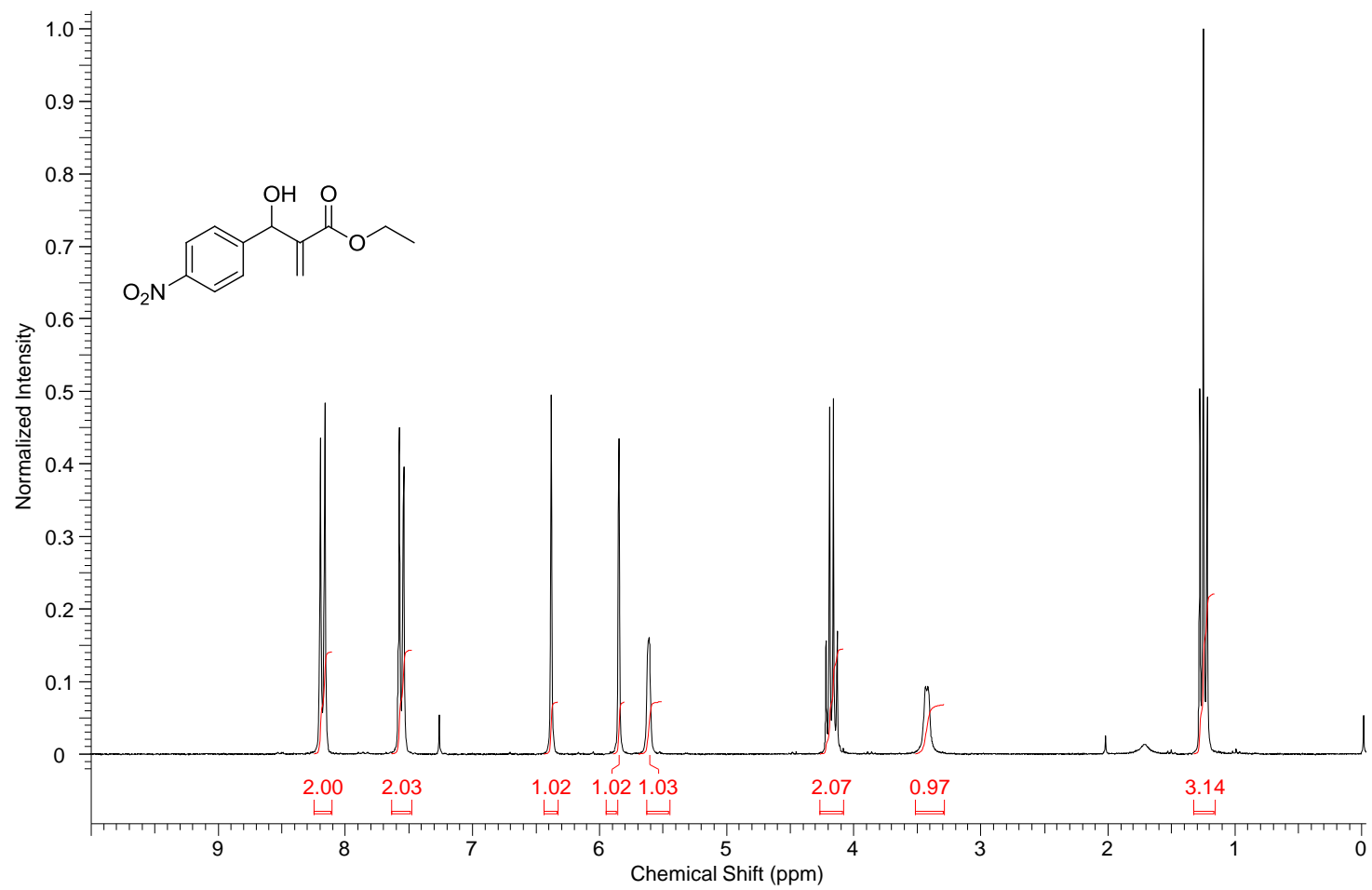

Figure S7. ${ }^{1} \mathrm{H}$ NMR $\left(250 \mathrm{MHz}, \mathrm{CDCl}_{3}\right)$ of $\mathrm{MBH}$ adduct $\mathbf{1 0 b}$.

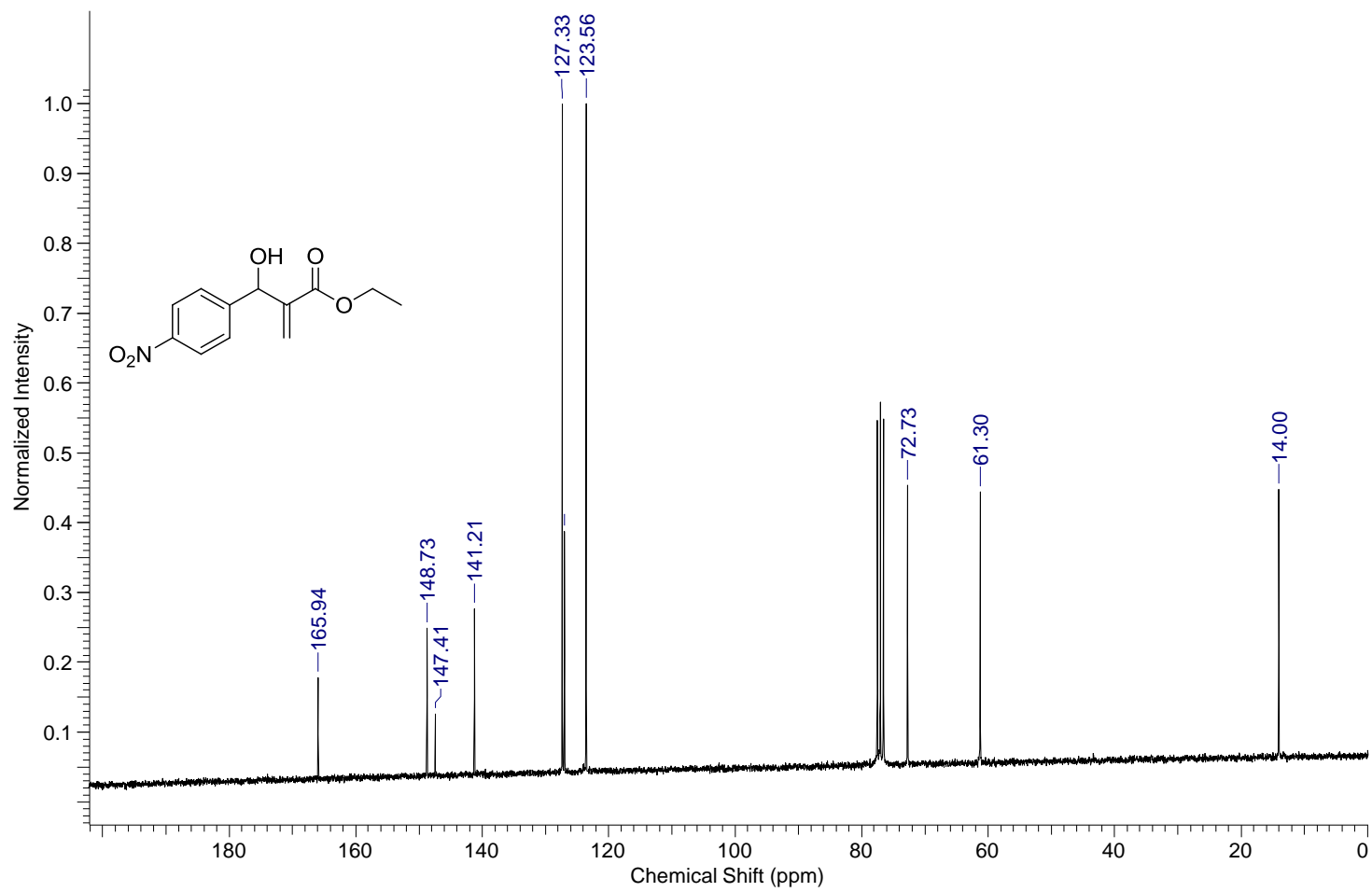

Figure S8. ${ }^{13} \mathrm{C}$ NMR $\left(62.5 \mathrm{MHz}, \mathrm{CDCl}_{3}\right)$ spectrum of $\mathrm{MBH}$ adduct $\mathbf{1 0 b}$. 


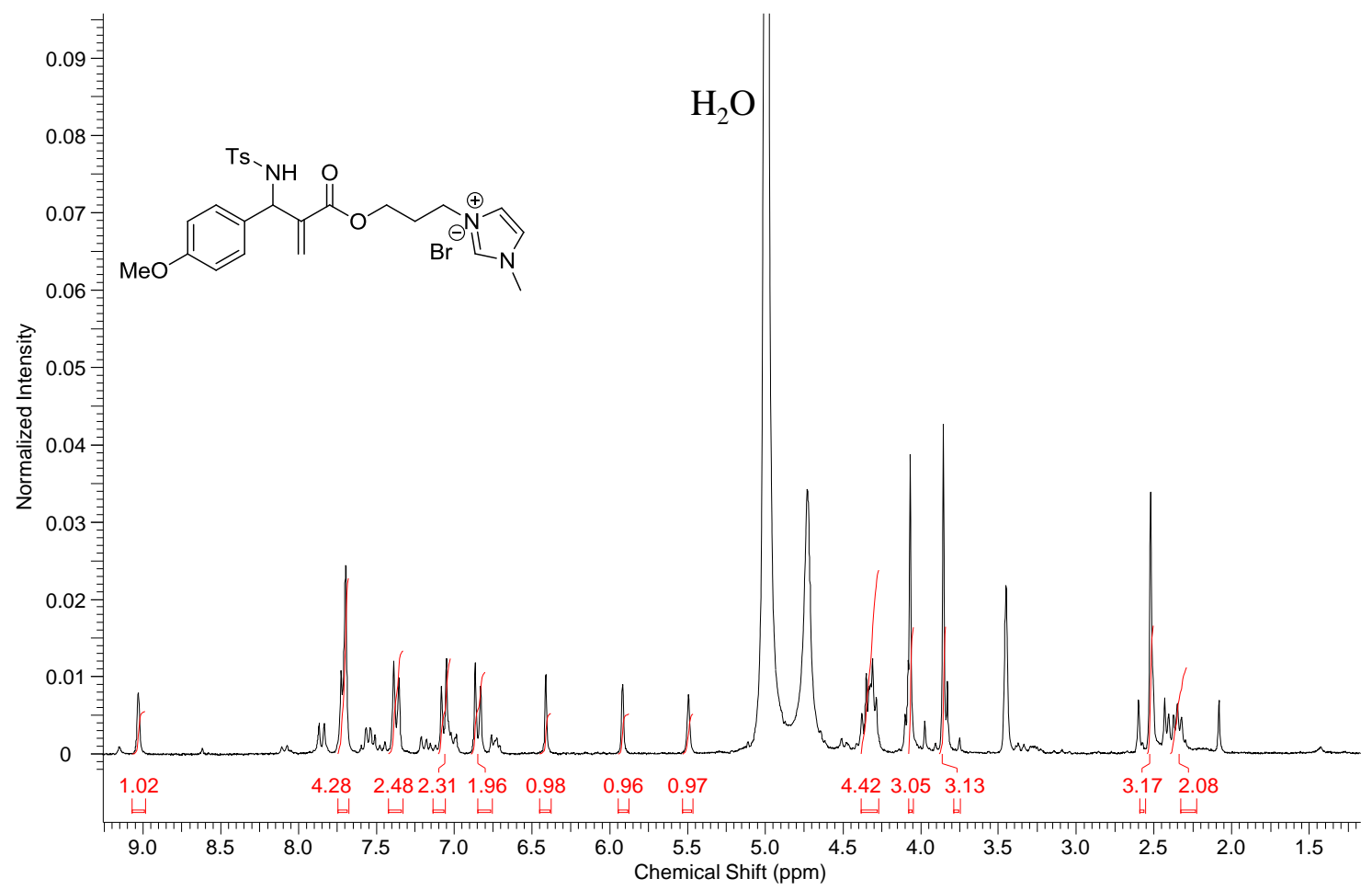

Figure S9. ${ }^{1} \mathrm{H} \mathrm{NMR}\left(250 \mathrm{MHz}, \mathrm{CD}_{3} \mathrm{OD}\right)$ spectrum of charge tagged $a z a-\mathrm{MBH}$ adduct 10c.

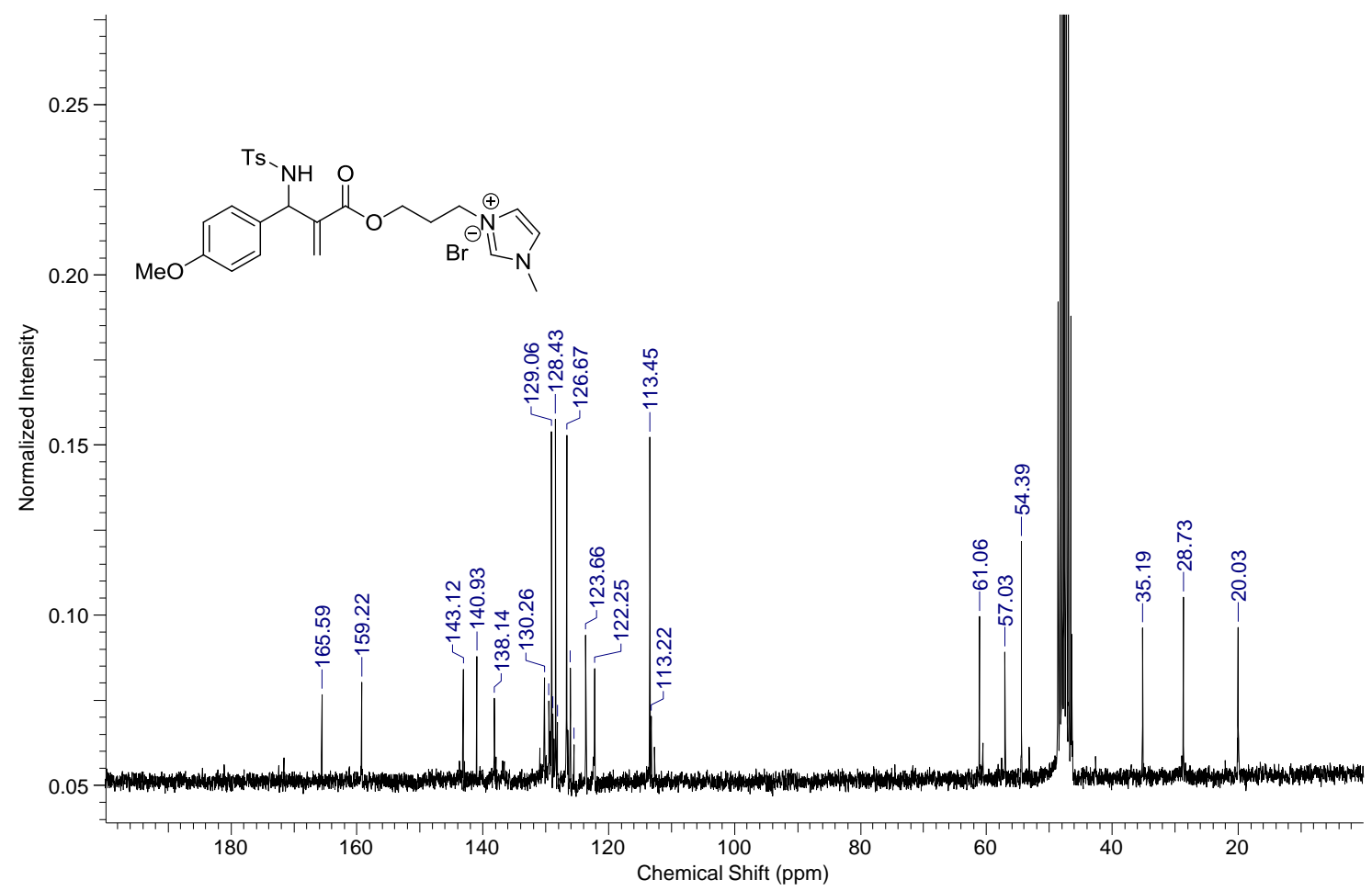

Figure S10. ${ }^{13} \mathrm{C}$ NMR $\left(62.5 \mathrm{MHz}, \mathrm{CD}_{3} \mathrm{OD}\right)$ spectrum of charge tagged aza-MBH adduct 10c. 


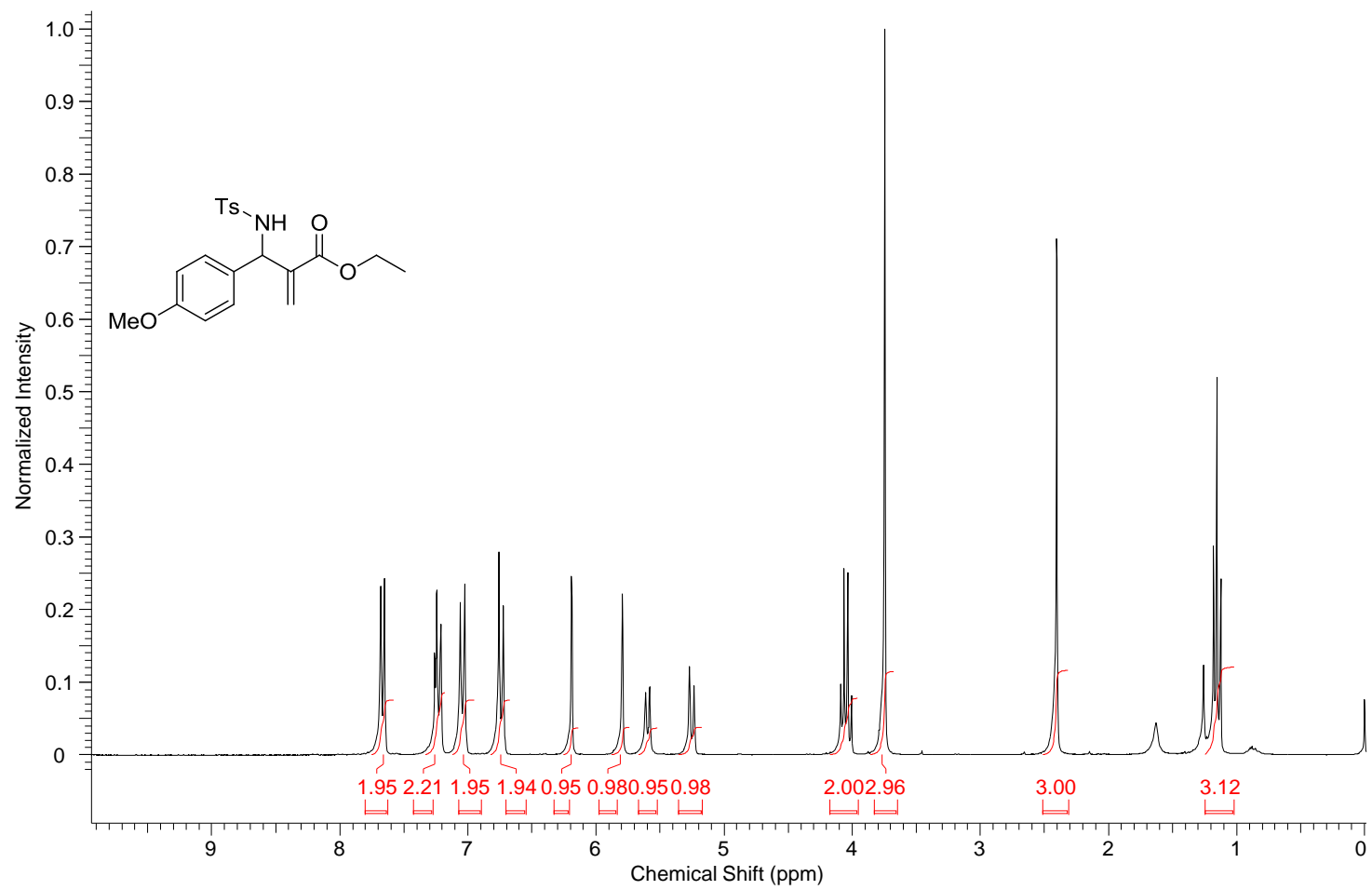

Figure S11. ${ }^{1} \mathrm{H}$ NMR $\left(250 \mathrm{MHz}, \mathrm{CDCl}_{3}\right)$ spectrum of $a z a-\mathrm{MBH}$ adduct 10d.

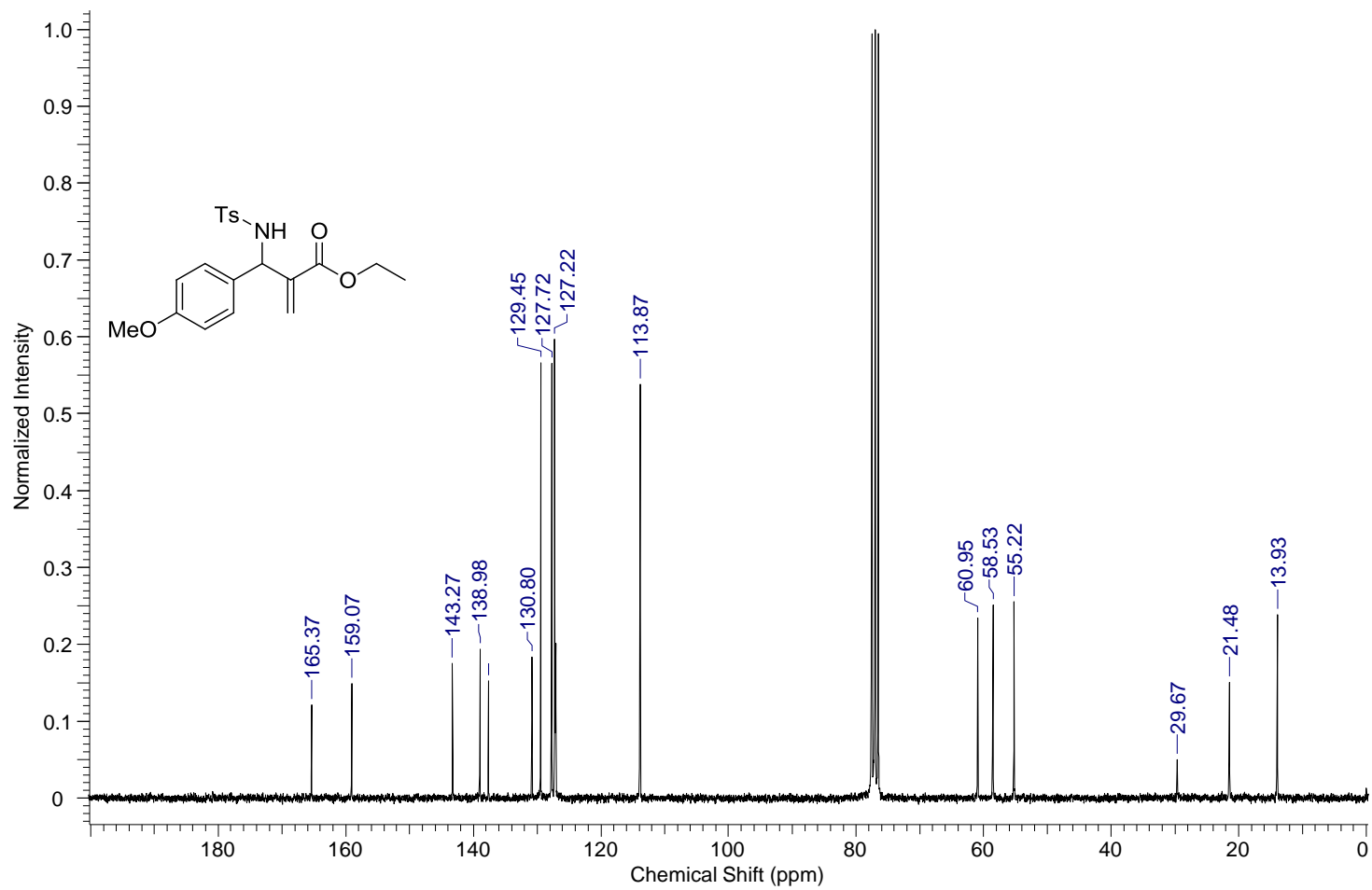

Figure S12. ${ }^{13} \mathrm{C}$ NMR $\left(62.5 \mathrm{MHz}, \mathrm{CDCl}_{3}\right)$ spectrum of aza-MBH adduct 10d. 
3. ESI(+)-MS monitoring using charge tagged benzaldehyde: Figure S13 shows the ESI(+)-MS for the classical MBH reaction using charge tagged benzaldehyde (7), ethyl acrylate (5b), DABCO (4a) as catalyst and acetonitrile as solvent. Note that just the enolate product ( $6 \mathbf{b}$, first intermediate of $\mathrm{m} / \mathrm{z}$ 213) and the final adduct (10e, of $\mathrm{m} / \mathrm{z}, 264)$ were detected. The aldol product (second intermediate, doubly charged ion of $\mathrm{m} / \mathrm{z}$ 188.6) and the hemiacetal intermediate described by McQuade (triply charged ion of $\mathrm{m} / \mathrm{z}$ 180.5) were not detected during the whole reaction monitoring. Others species were however detected, such as those of $\mathrm{m} / \mathrm{z}, 353,404$ and 455 . They were attributed as a series of aggregates as we described: Two protonated catalyst with an iodine counterion of $\mathrm{m} / z, 353\left[\mathrm{I}^{-}+(\mathrm{DABCO}+\mathrm{H})_{2}\right]^{+}$, protonated catalyst and charge tagged benzaldehyde with a iodine counterion of $m / z 404\left[(\mathrm{DABCO}+\mathrm{H})+\mathrm{I}^{-}+(\text {Benzaldehyde })\right]^{+}$and two charge tagged benzaldehyde with o iodine counterion of $\mathrm{m} / z 455$ ( Benzaldehyde) ${ }_{2}+\mathrm{I}^{-}$ )$^{+}$.

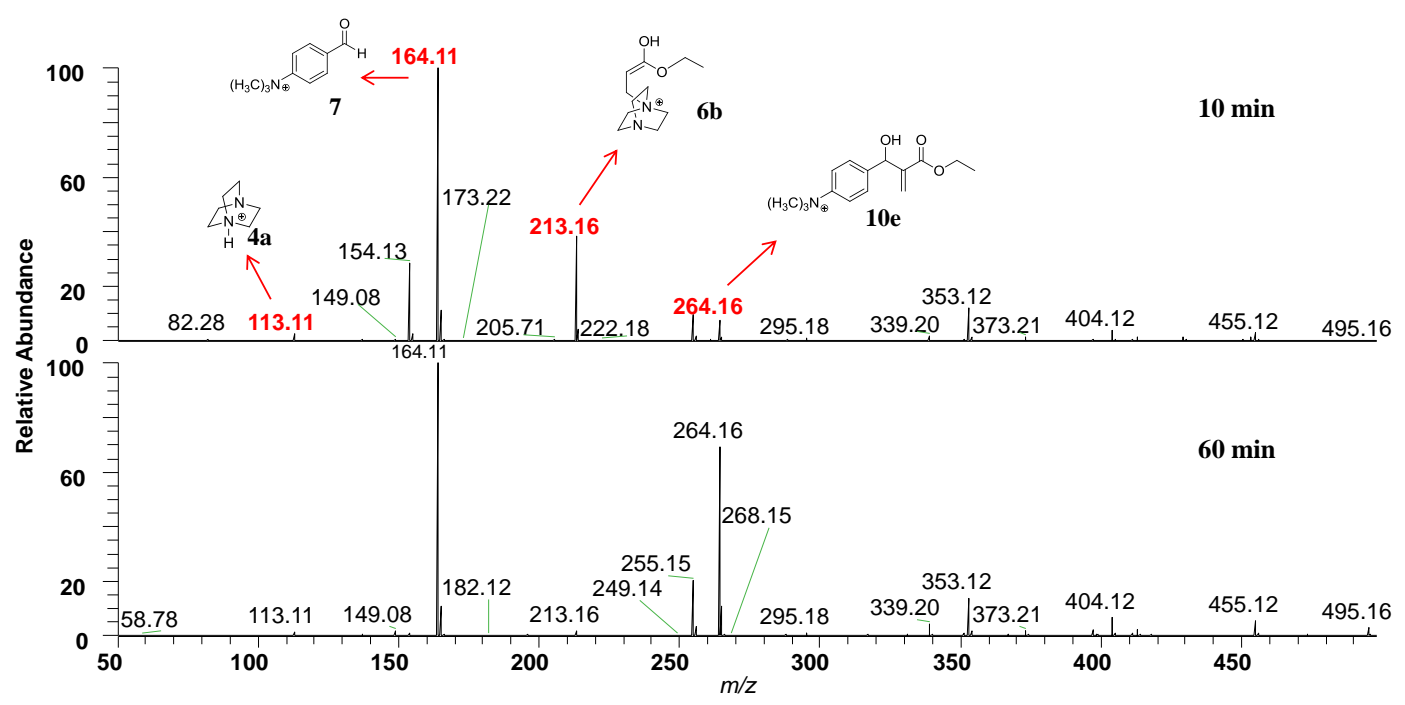

Figure S13. ESI(+)-MS of the classical MBH reaction solution at $10 \mathrm{~min}$ (top) and $60 \mathrm{~min}$ (bottom) using charge tagged benzaldehyde.

Scheme S1 shows the disfavors/unstable aldol product (second intermediate) and hemiacetal not detected by $\mathrm{ESI}(+)-\mathrm{MS}$ in the $\mathrm{MBH}$ reaction using charge tagged benzaldehyde as electrophile. Note the proximity of the positive charge in these structures. 


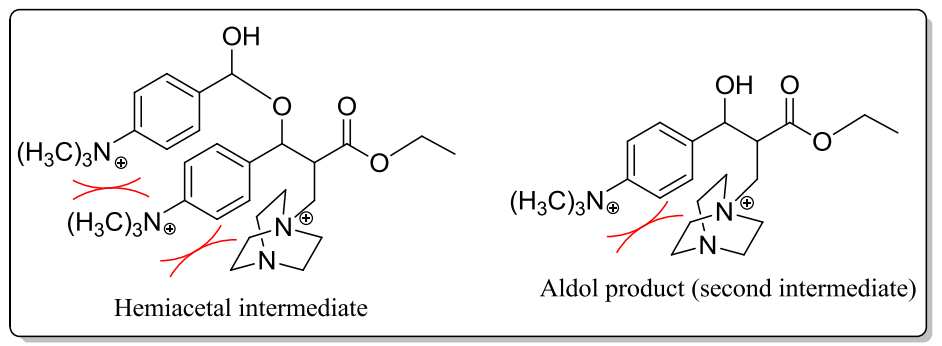

Scheme S1. Disfavors/unstable aldol and hemiacetal intermediates.

\section{Participation of the charge tagged acrylate on the mechanism of the MBH/aza-MBH} reactions: The co-catalyst action of the methylimidazolium ion for the acrylate 5a could be rationalized as contributing in the mechanism steps as Scheme 5 rationalizes below.

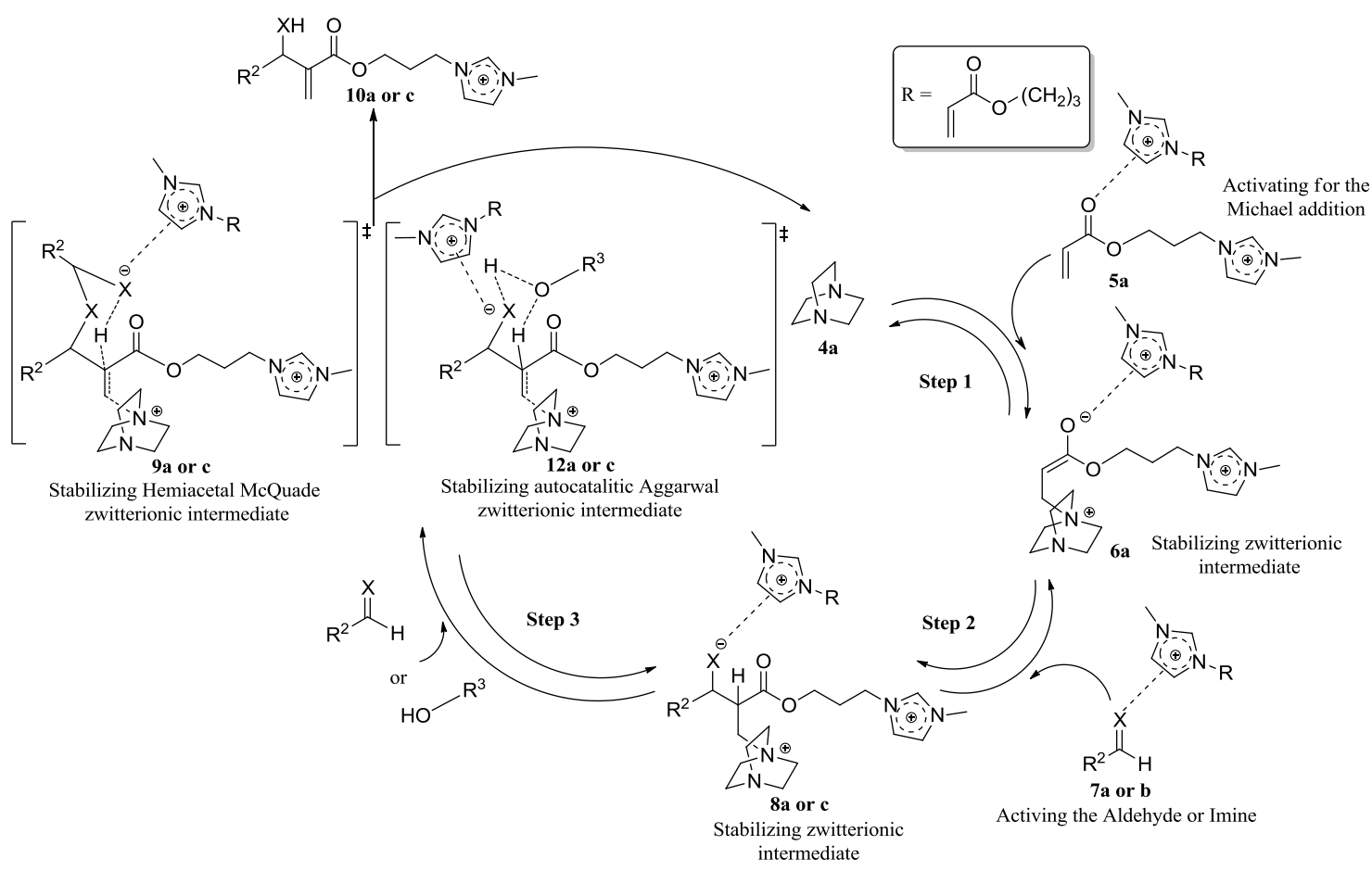

Scheme S2. Global participation of the charge tagged acrylate 5a on the mechanism of the $\mathrm{MBH} / a z a-\mathrm{MBH}$ reactions. 
5. ESI(+)-MS/MS and accurate mass measurements for the main species detected in the monitoring of the neutral and charge tagged MBH/aza-MBH reactions.
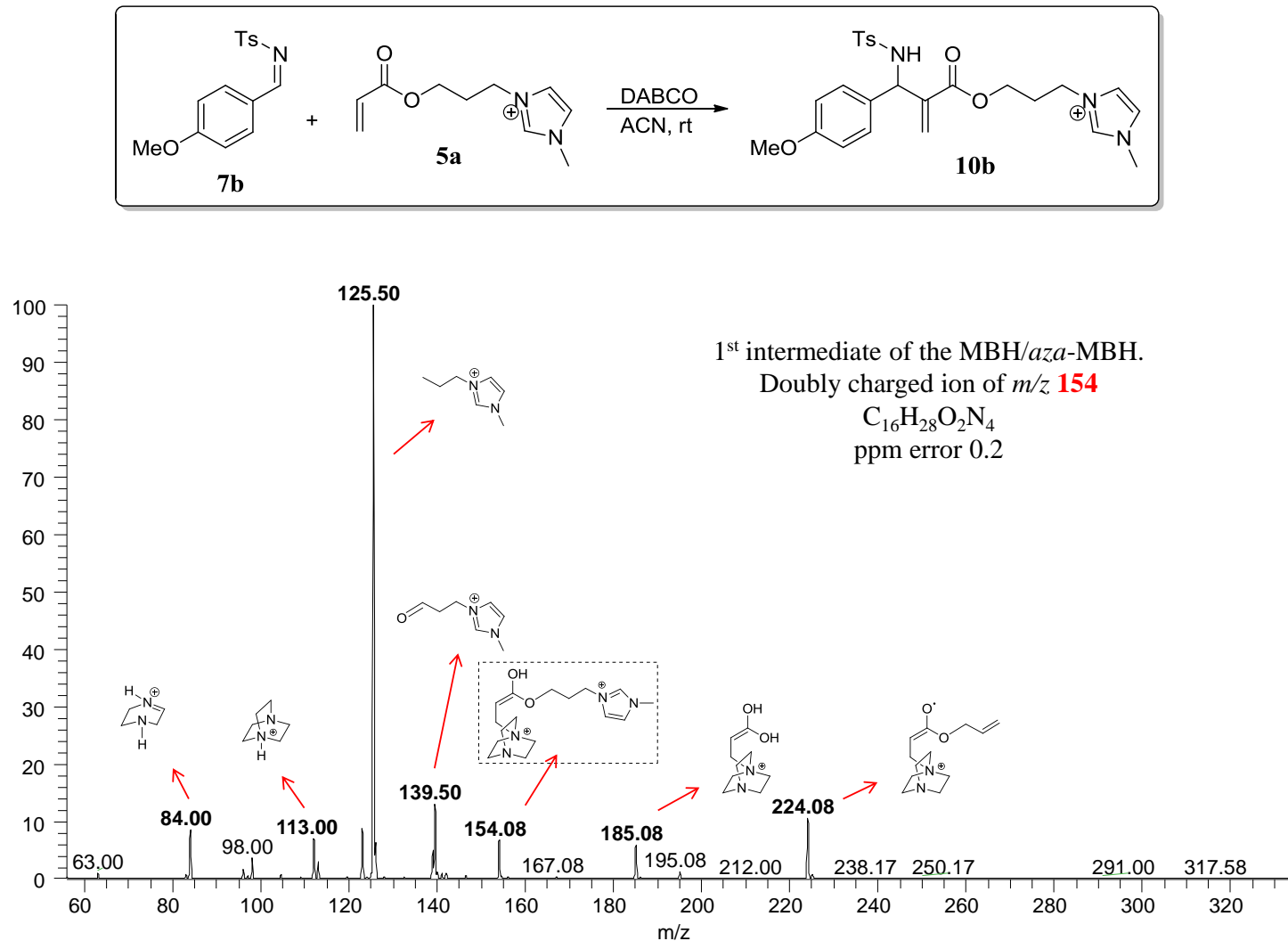

Figure S14. ESI(+)-MS/MS of enolate product from $\mathrm{MBH} / a z a-\mathrm{MBH}$ reactions (charge tagged reactions)

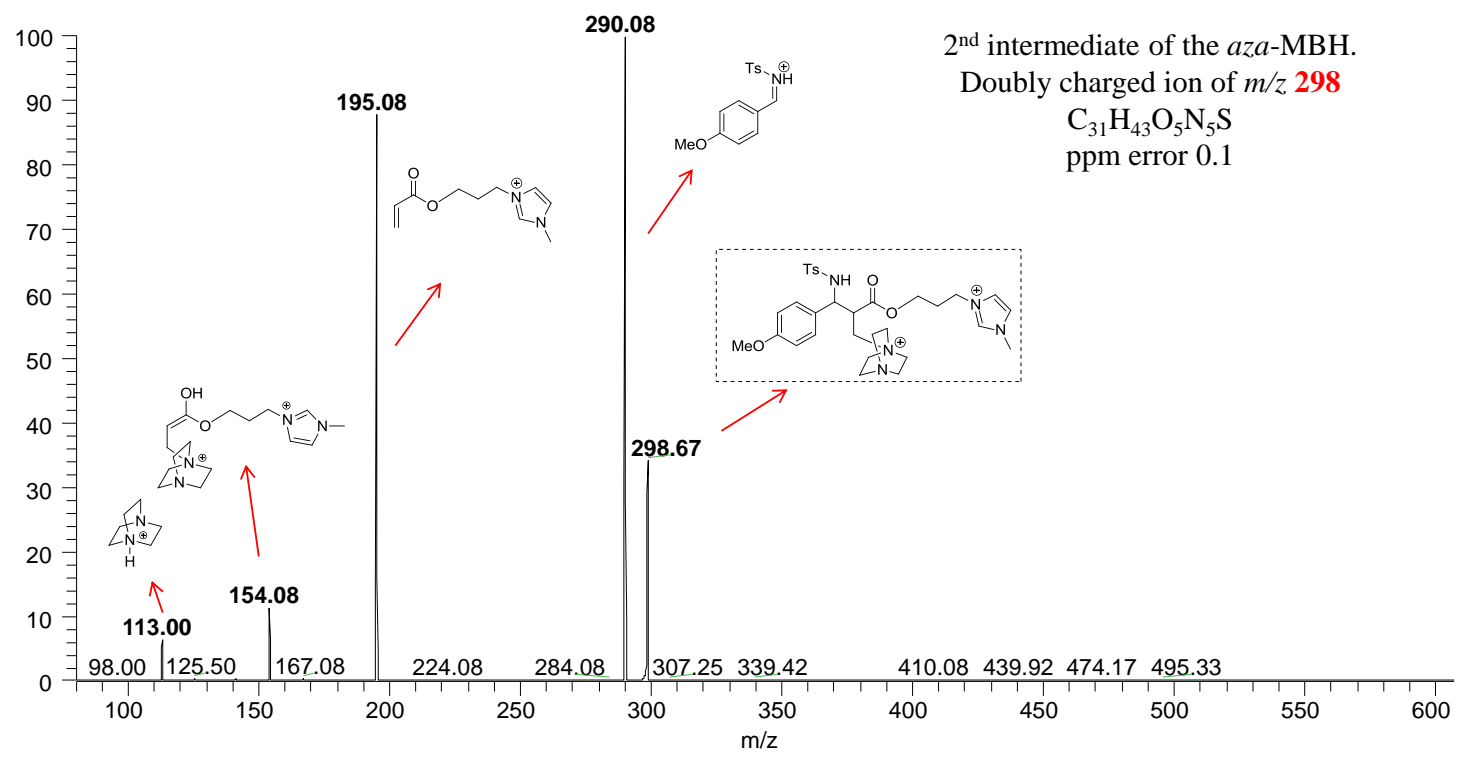

Figure S15. ESI(+)-MS/MS of aldol product from $a z a-\mathrm{MBH}$ reaction (charge tagged reaction) 


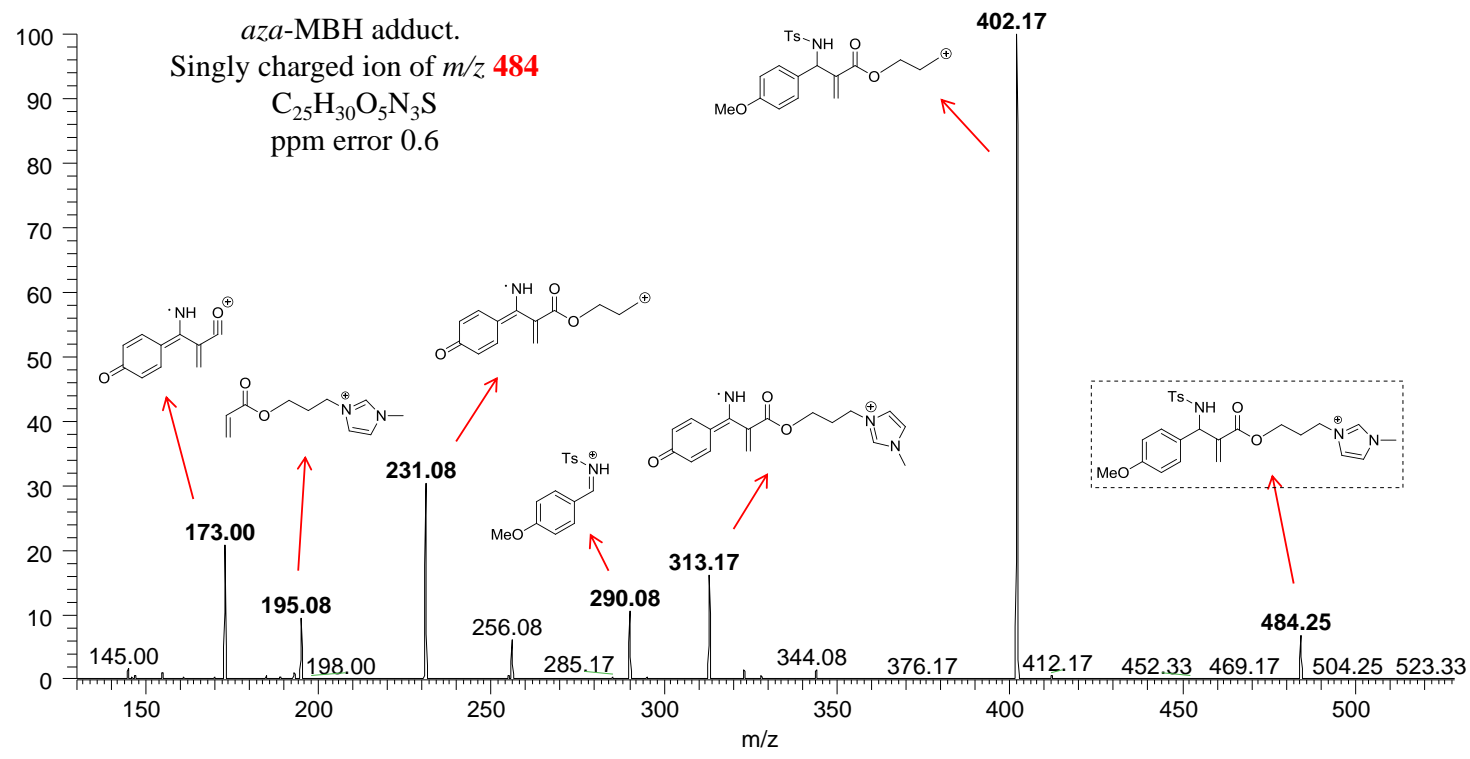

Figure S16. ESI(+)-MS/MS of $a z a-\mathrm{MBH}$ adduct (charge tagged reaction)

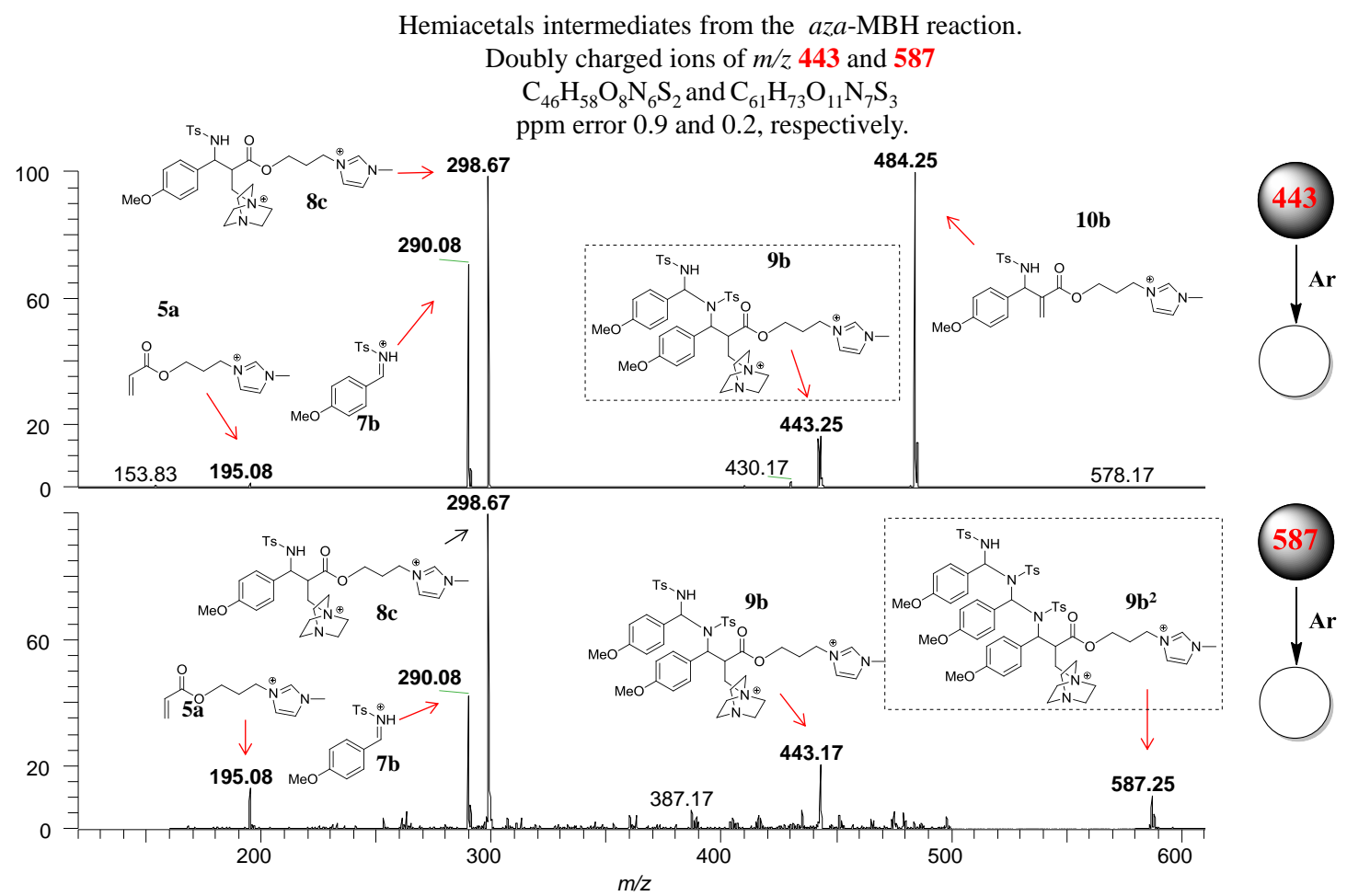

Figure S17. ESI(+)-MS/MS of hemiacetals from the $a z a-\mathrm{MBH}$ reaction (charge tagged reaction). 


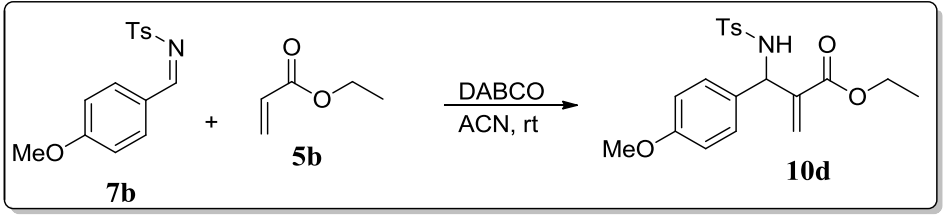

185.25

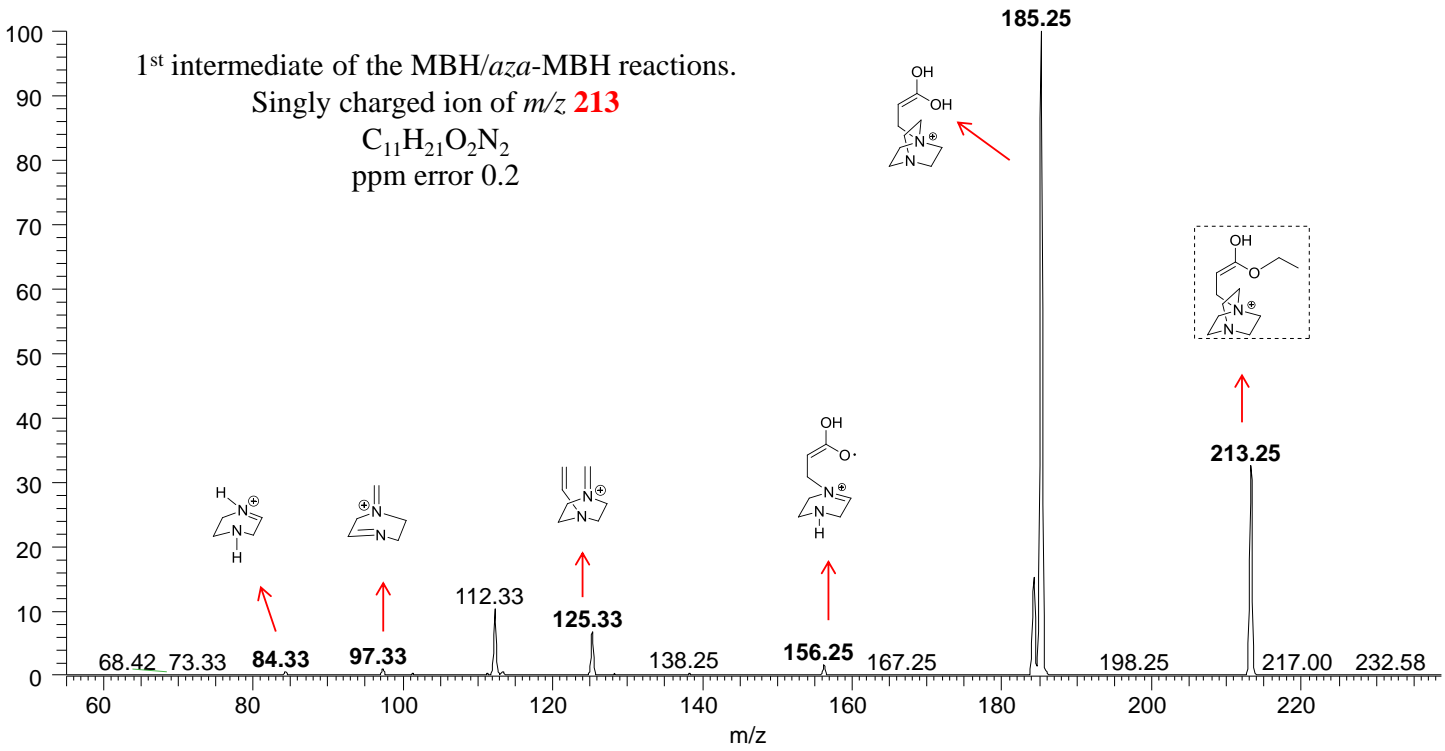

Figure S18. ESI(+)-MS/MS of enolate product from $\mathrm{MBH} / a z a-\mathrm{MBH}$ reactions (neutral reactions)

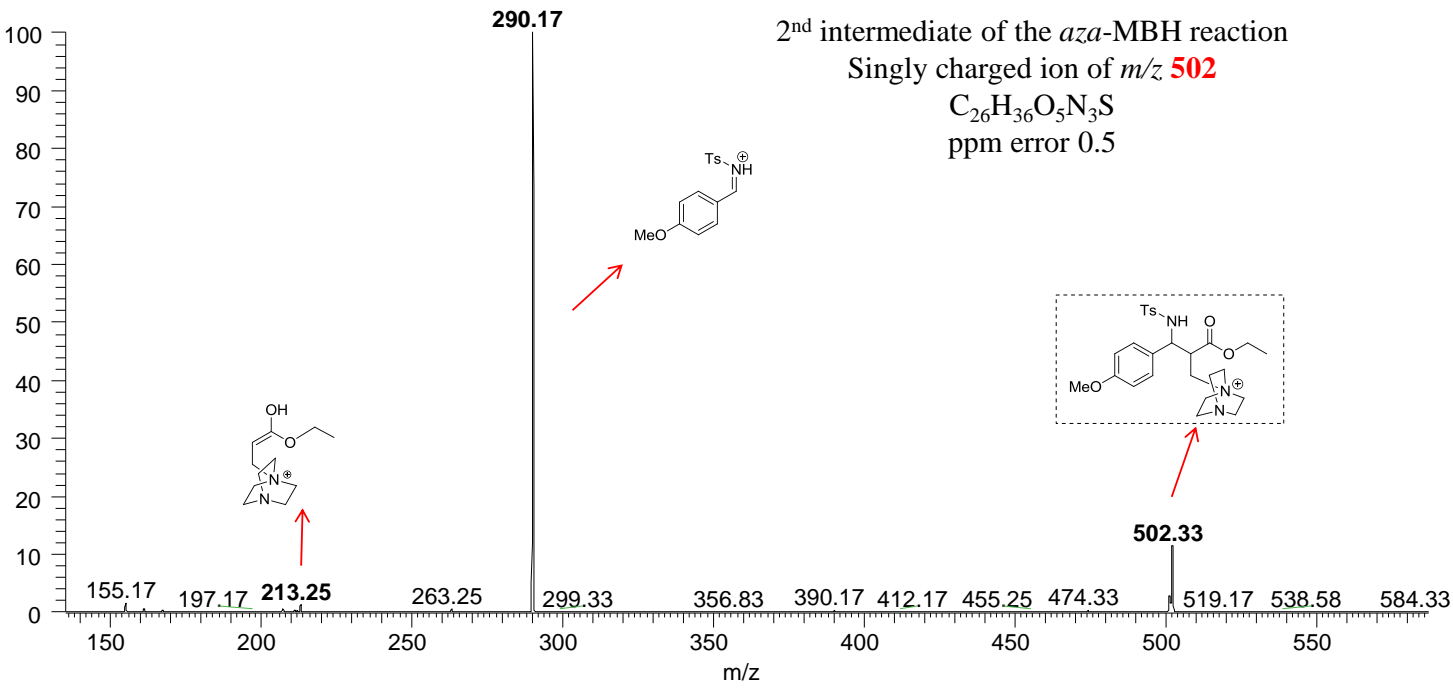

Figure S19. ESI(+)-MS/MS of aldol product from $a z a-\mathrm{MBH}$ reaction (neutral reaction). 

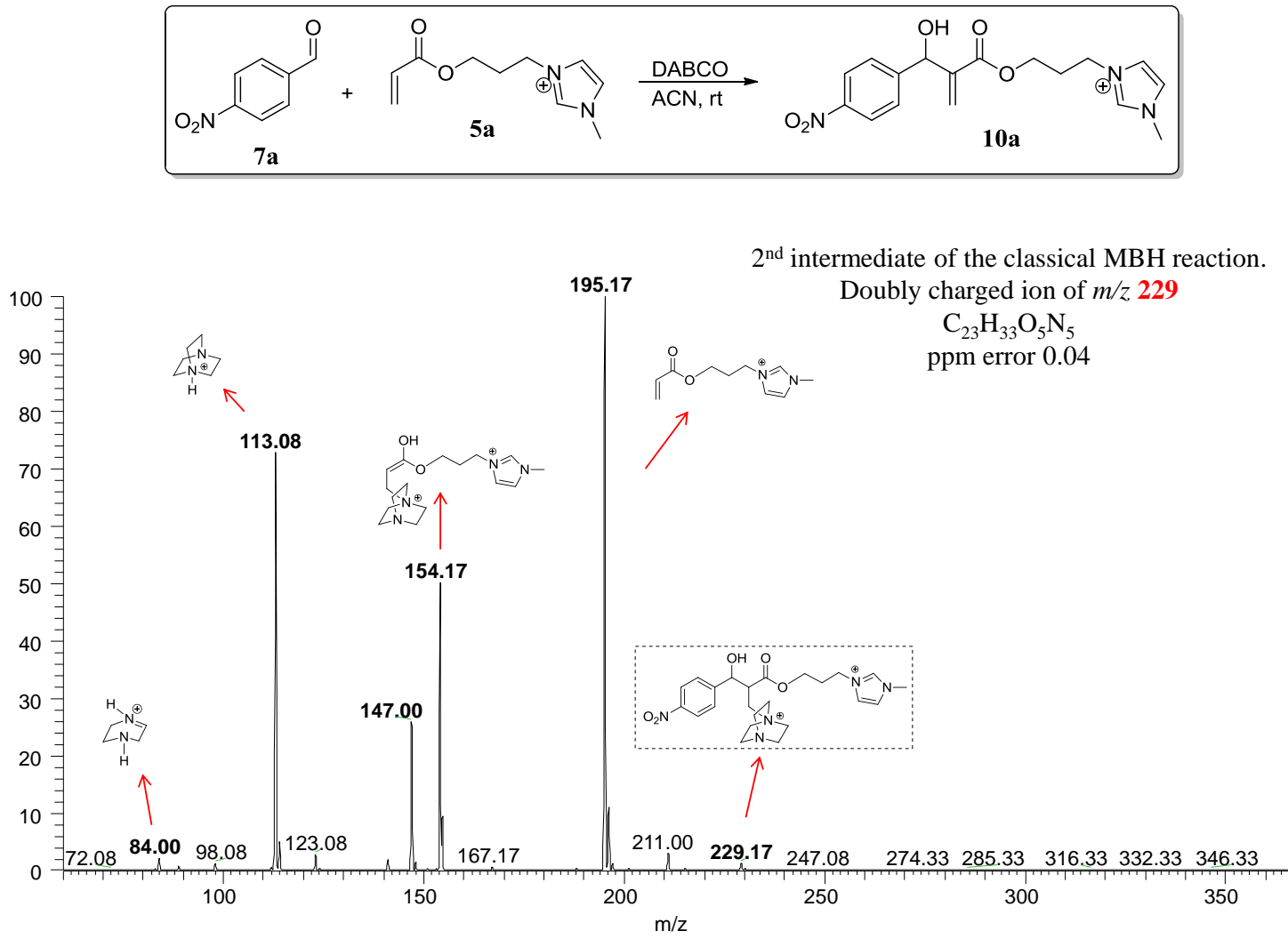

Figure S20. ESI(+)-MS/MS of aldol product from MBH reaction (charge tagged reaction)

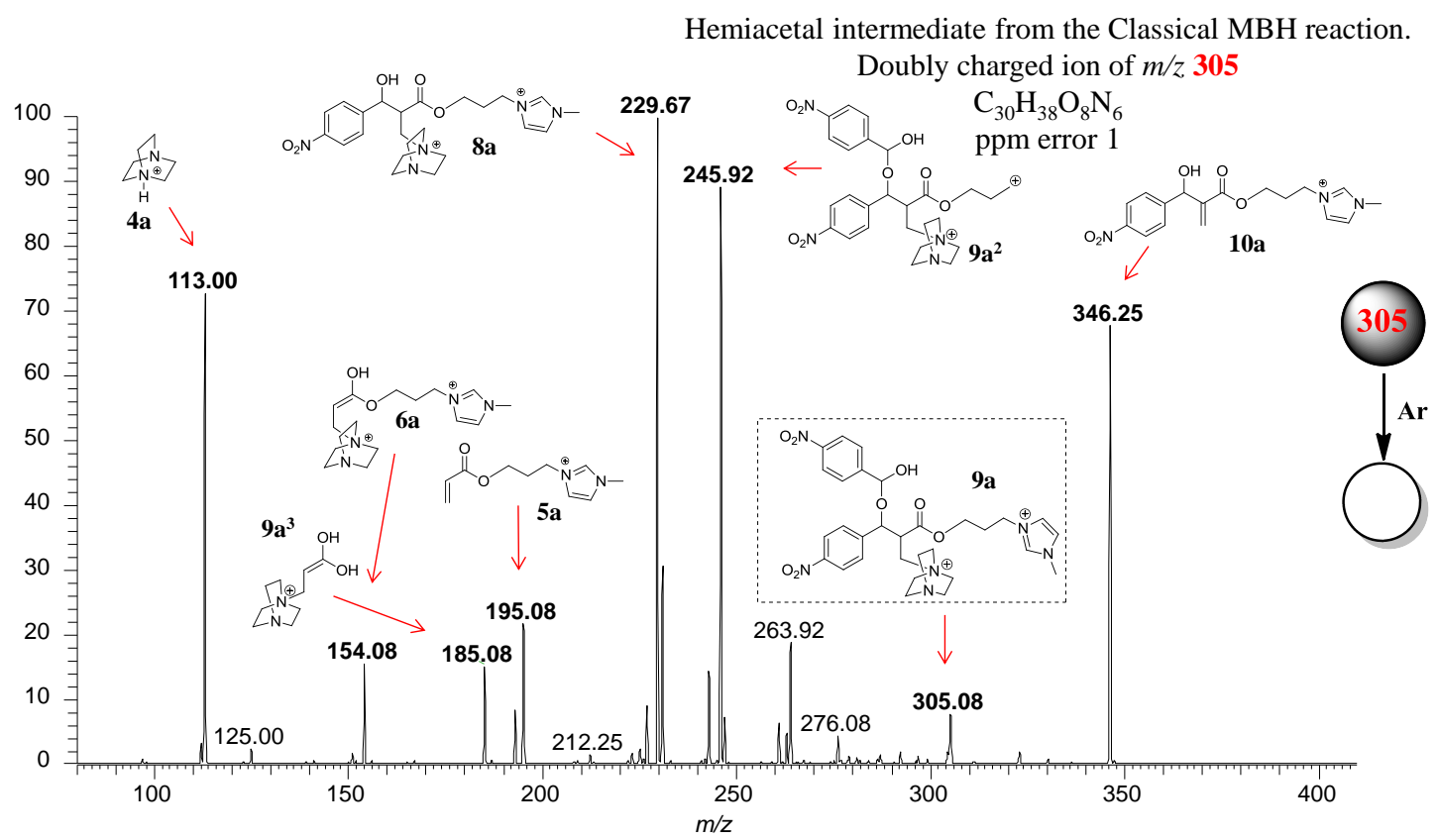

Figure S21. ESI(+)-MS/MS of hemiacetal from MBH reaction (charge tagged reaction) 


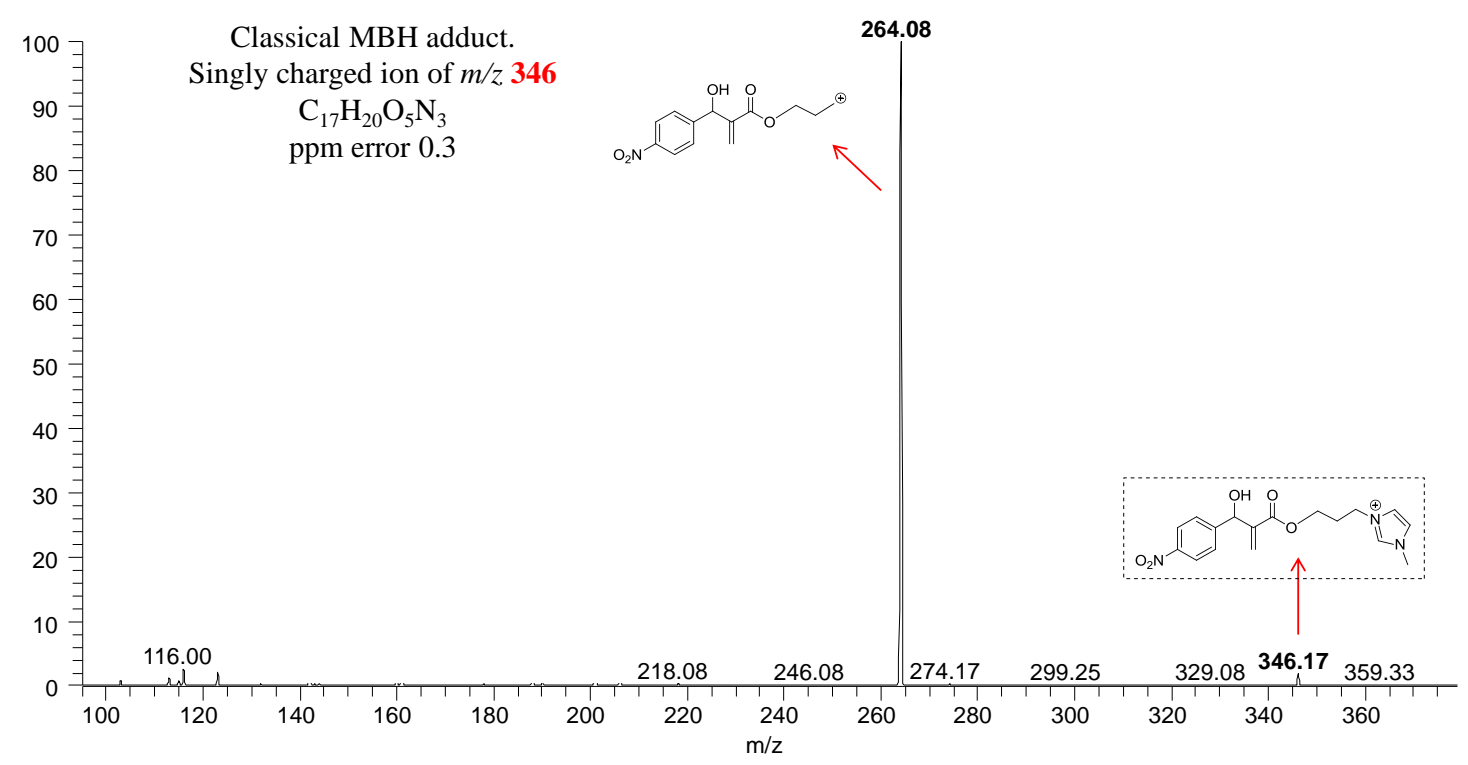

Figure S22. ESI(+)-MS/MS of MBH adduct (charge tagged reaction)
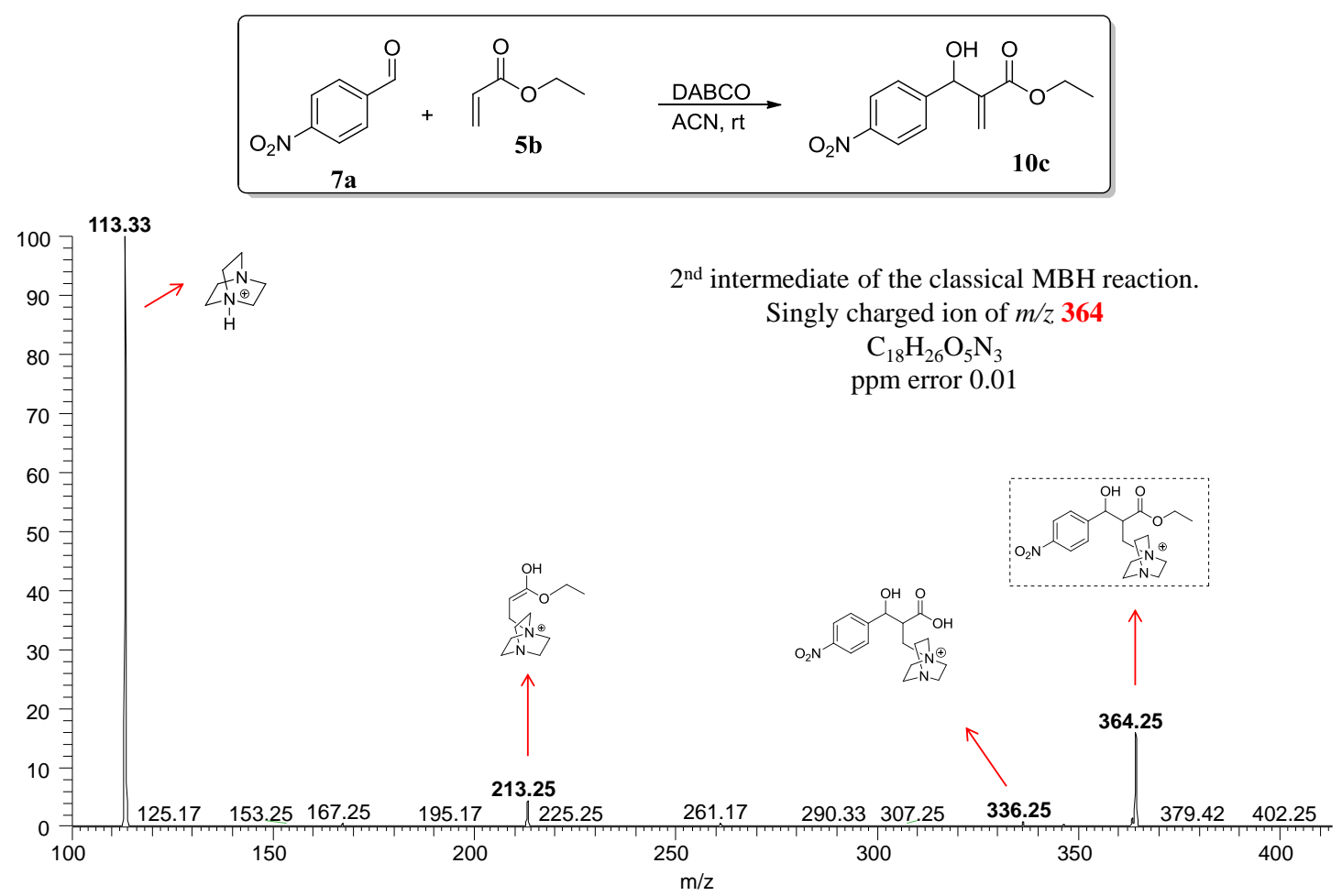

Figure S23. ESI(+)-MS/MS of aldol product from MBH reaction (neutral reaction) 


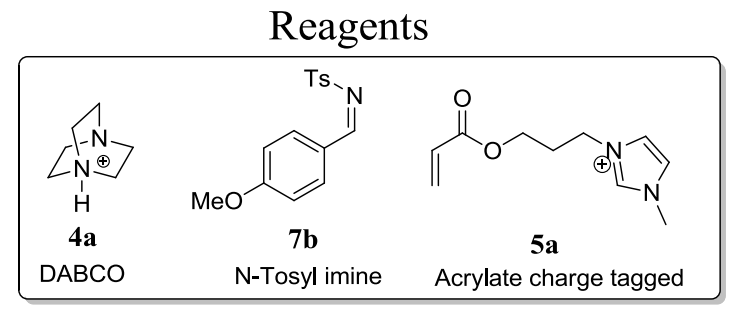

DABCO catalyst.

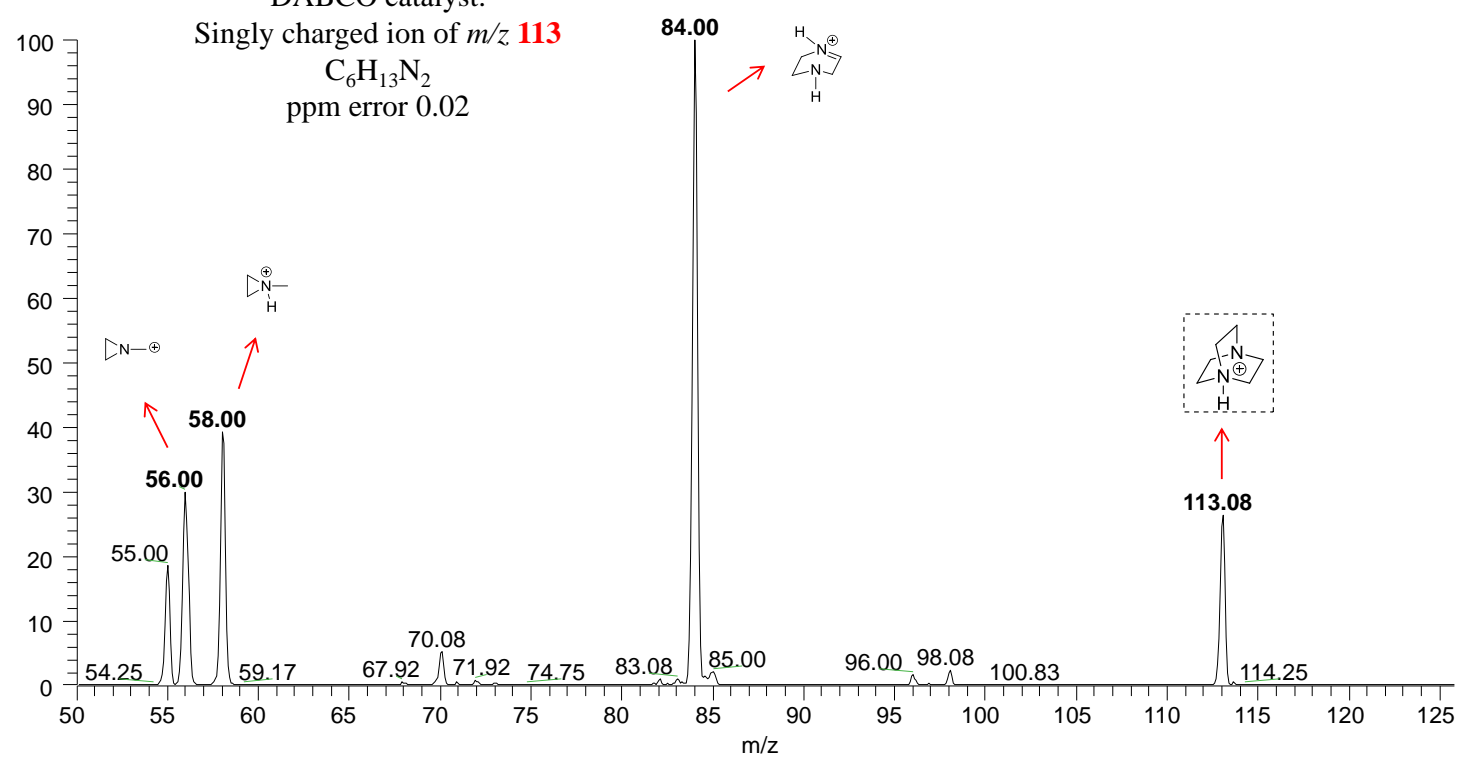

Figure S24. ESI(+)-MS/MS of protonated catayst DABCO.

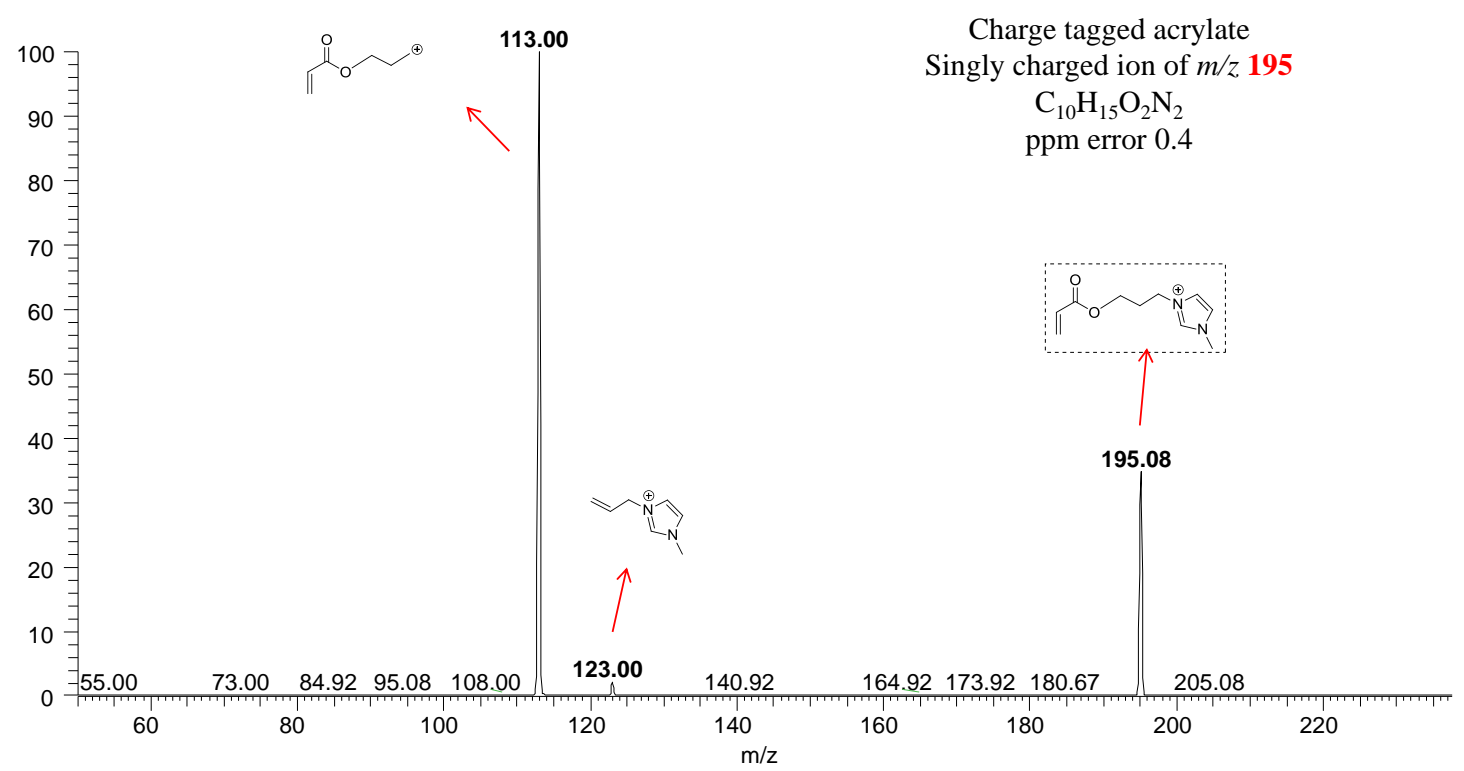

Figure S25. ESI(+)-MS/MS of charge tagged acrylate 5a. 


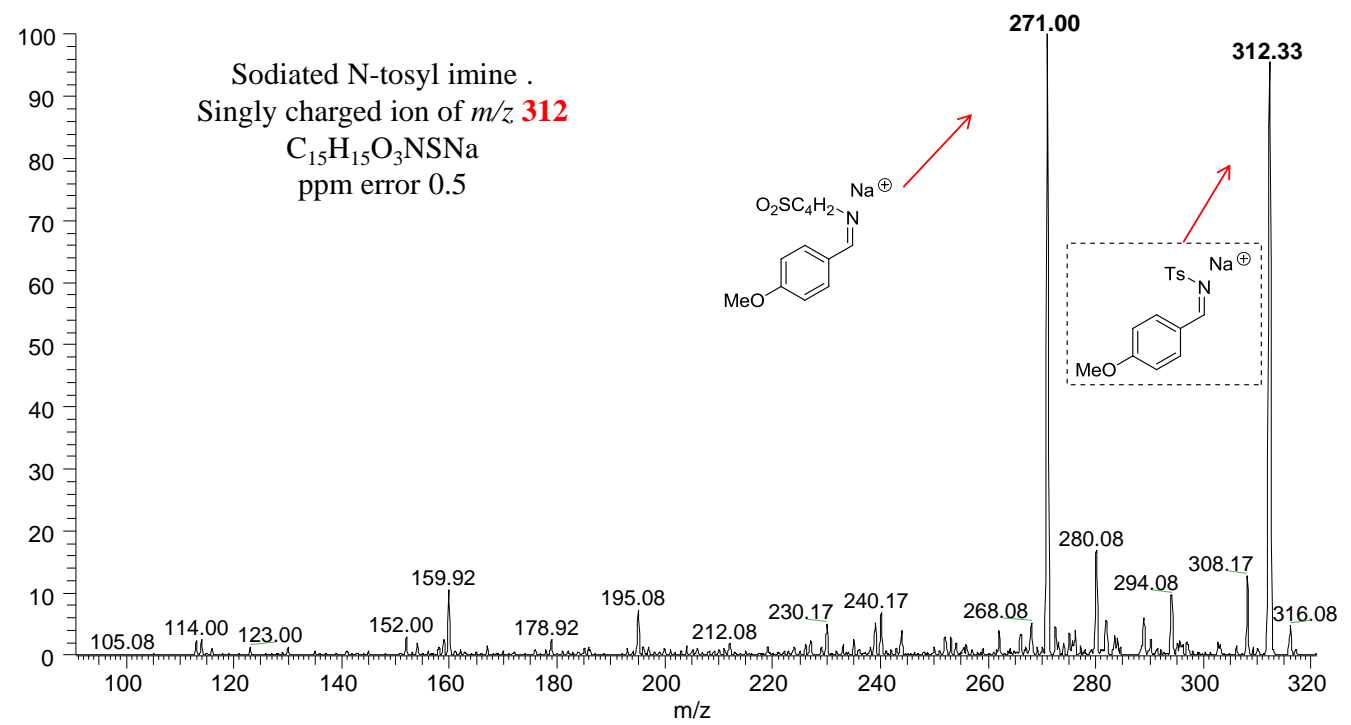

Figure S26. ESI(+)-MS/MS of sodiated N-tosyl imine.
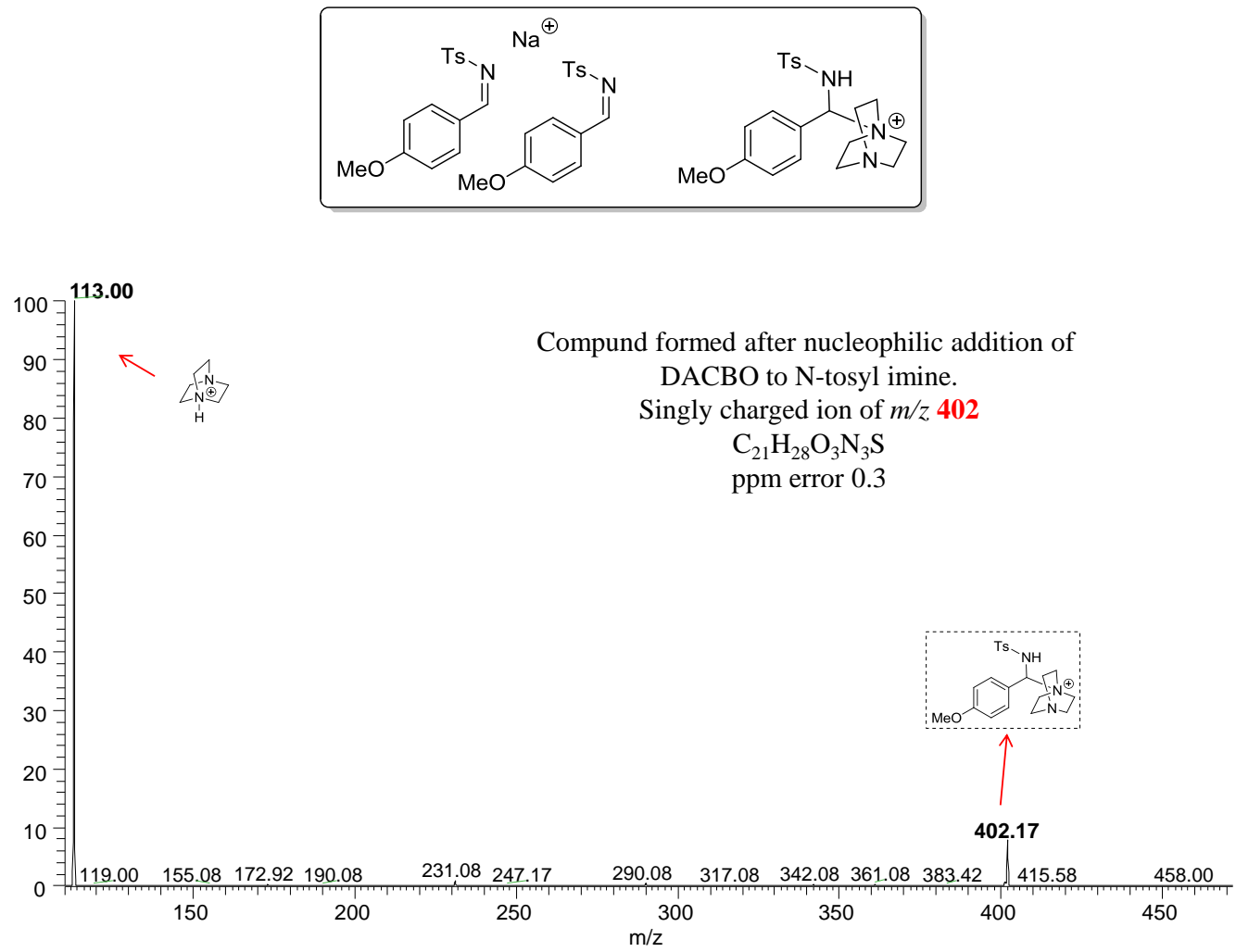

Figure S27. ESI(+)-MS/MS of compound formed by attack of DABCO to the N-tosyil imine. 


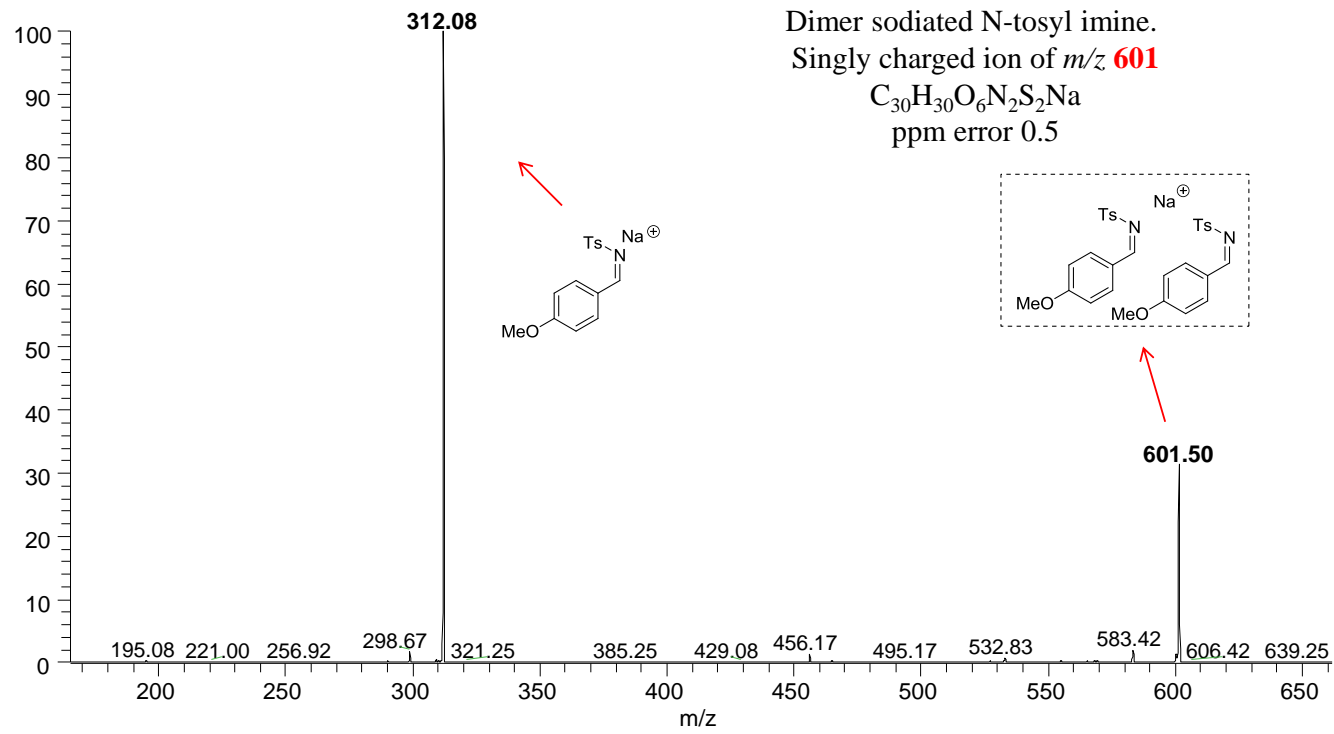

Figure S28. ESI(+)-MS/MS of dimer sodiated N-tosyl imine. 